\title{
Visual Illusions: An Interesting Tool to Investigate Developmental Dyslexia and Autism Spectrum Disorder
}

\author{
Simone Gori ${ }^{1,2 *}$, Massimo Molteni ${ }^{2}$ and Andrea Facoetti ${ }^{2,3}$ \\ ${ }^{1}$ Department of Human and Social Sciences, University of Bergamo, Bergamo, Italy, ${ }^{2}$ Child Psychopathology Unit, Scientific \\ Institute, IRCCS Eugenio Medea, Bosisio Parini, Italy, ${ }^{3}$ Developmental and Cognitive Neuroscience Lab, Department of \\ General Psychology, University of Padova, Padua, Italy
}

A visual illusion refers to a percept that is different in some aspect from the physical stimulus. Illusions are a powerful non-invasive tool for understanding the neurobiology of vision, telling us, indirectly, how the brain processes visual stimuli. There are some neurodevelopmental disorders characterized by visual deficits. Surprisingly, just a few studies investigated illusory perception in clinical populations. Our aim is to review the literature supporting a possible role for visual illusions in helping us understand the visual deficits in developmental dyslexia and autism spectrum disorder. Future studies could develop new tools - based on visual illusions - to identify an early risk for neurodevelopmental disorders.

Keywords: illusory effect, perception, attention, autistic traits, reading disorder

\section{OPEN ACCESS}

Edited by:

Baingio Pinna,

University of Sassari, Italy

Reviewed by:

Susana Martinez-Conde,

State University of New York, USA

John Frederick Stein,

University of Oxford, UK

Irene Sperandio,

University of East Anglia, UK

*Correspondence:

Simone Gori

simone.gori@unibg.it

Received: 31 August 2014 Accepted: 06 April 2016

Published: 25 April 2016

Citation:

Gori S, Molteni M and Facoetti A (2016) Visual Illusions: An Interesting

Tool to Investigate Developmental

Dyslexia and Autism Spectrum

Disorder.

Front. Hum. Neurosci. 10:175.

doi: 10.3389/fnhum.2016.00175

\section{VISUAL ILLUSION AS A TOOL TO INVESTIGATE BRAIN PROCESSING}

A visual illusion refers to a percept that is different from what would be typically predicted based on the physical stimulus. Illusory perception is often experienced as a real percept. Illusory motion should not be confused with the perception of dynamism evoked by paintings (Gori et al., 2008b), or by the speed lines often used in comic books (Burr, 2000). On the contrary, the observer's percept is usually phenomenally indistinguishable from real motion (see Kitaoka and Ashida, 2007; Gori and Stubbs, 2014, for a review on motion illusions).

Visual illusions reflect the constraints developed by our visual system, through evolution, to support the efficient formation of visual representations that are also sufficient in describing our external environment (see Eagleman, 2001, for a review). For example, such constraints allow us to perceive the constant illusion of a stable perceptual world, despite our receptors continuously signaling motion due to eye, head, and body movements. Consequently, it is quite difficult to provide a rigorous definition of "visual illusion", since our visual experiences are, in effect, always an illusion (Eagleman, 2001; Rogers, 2014). As nicely described by Spillmann (2009), visual illusions show "the brain's signature superimposed upon the stimulus". Thus, visual illusions provide a powerful, non-invasive means by which to investigate our brain mechanisms.

There are numerous types of visual illusions, and they can roughly categorized by their perceptual appearance, including brightness (e.g., Pinna et al., 2003; Gori and Stubbs, 2006; Todorović, 2006; Anstis et al., 2007; Spillmann et al., 2010; Galmonte et al., 2015), color (e.g., Varin, 1971; Pinna et al., 2001), size (e.g., Sperandio et al., 2010, 2012, 2013; Sperandio and Chouinard, 2015), etc. (see Gregory, 1968, 1997). However, illusion classification did not reach a general 
consensus yet (see Hamburger, 2016, for a recent review). Measuring a visual illusion, even if it sounds counterintuitive, can be done in a very accurate way in both human and nonhuman species (e.g., Macknik and Livingstone, 1998; Conway et al., 2005; Gori et al., 2006, 2008a, 2010a,b, 2014; Fantoni and Pinna, 2008; Giora and Gori, 2010; Gori and Spillmann, 2010; Spillmann et al., 2010; Hamburger, 2012; Ito, 2012; Otero-Millan et al., 2012; Shi et al., 2013; Agrillo et al., 2015). Following the everyman's perspective, visual illusions could not be considered a good tool for investigating perceptual differences in groups because they are "subjective". "Subjective" would mean that the observer response would be based on her/his perceptual outcome and also on her/his response criterion. On the contrary, following this naive interpretation, tasks based on physical differences in the stimuli would be "objective". This distinction is based on the wrong assumption so-called, "naive realism", which implies that perception faithfully reflects the stimulus at the retina level (Spillmann, 2009). Such an approach fails to consider the fact that performance in behavioral tasks reflect processing wellbeyond that of our low-level visual systems, e.g., retinal processes. Consequently, the supposed "objective" task will be subjective exactly like a "subjective" task, because they are both a result of a mixture of perceptual processing and response criteria. As a side note, any motion stimulus presented on a computer screen is illusory motion exactly like cinema is. Thus, almost all the motion studies in the last 30 years are based on illusory motion instead of real motion.

In summary, the use of visual illusions to investigate brain processing and perceptual differences among groups in behavioral studies of perception is legit exactly like employing ordinary stimuli. Moreover, measures of visual illusions can provide much more information about neural mechanisms than ordinary stimuli due to their ability to highlight the visual system constraints. Over the course of vision science history, several illusions successfully provided the first intuition of how the brain processes a stimulus or the tool to investigate the neurobiological characteristics of the visual system (see Eagleman, 2001, for a review).

Although the study of clinical populations and the world of visual illusions may not seem very connected, there have been some excellent advancements resulting from their joint study. For example, Notredame et al. (2014) recently reviewed the contribution of visual illusions in understanding schizophrenia. Here, we aim to review the literature using visual illusions to understand two of the most studied neurodevelopmental disorders: developmental dyslexia (DD) and autism spectrum disorder (ASD). Our choice of DD and ASD primarily stems from reports of peculiar visual abilities characterizing these clinical populations. Consequently, they seems perfect candidate disorders for investigation by visual illusions. Relevant articles for this review were obtained through a keyword search of the PubMed database, with dyslexia AND visual illusions" and "autism AND visual illusions" as search terms.

In addition to our review, we provide ideas for potential new horizons and the advancement of DD and ASD research through the study of visual illusions.

\section{VISUAL DEFICITS IN DEVELOPMENTAL DYSLEXIA}

DD is often defined as a deficit in reading acquisition despite normal intelligence and access to conventional instruction (e.g., American Psychiatric Association Task Force on DSM-IV, 1994). However, some variations in the definition of DD are present. For example, the U.S. National Institutes of Health define DD as a learning disorder (NINDS, 2001/2015). One of the worldwide used manual of medical diagnosis ICD 10 (1992) includes separate diagnoses for DD and for "dyslexia and alexia". The latest version of the U.S. manual of psychiatric diagnosis (American Psychiatric Association Task Force on DSM-V, 2013), does not specifically define DD including that in a larger category called specific learning disorders.

Several attempted to account for DD, two main views, however, received major support. The first approach proposes that DD arises from deficits in systems that are specifically linguistic in nature. In particular, the phonological deficit theory suggests that DD arises from deficits in phonological processing (e.g., Goswami, 2003). In contrast, many authors suggest that disorders in underlying non-linguistic sensory mechanisms are the real core deficit in DD (e.g., Stein and Walsh, 1997; Vidyasagar and Pammer, 2010; Facoetti, 2012; Gori and Facoetti, 2014, 2015; for visual deficits; Wright et al., 2000; Tallal, 2004, for auditory deficits).

This theory, known as the temporal processing hypothesis, is the multisensory (i.e., visual and auditory) version of the magnocellular dorsal (M-D) theory of DD. This theory suggests that children with DD have deficits in rapid processing in visual and auditory modalities (see Farmer and Klein, 1995; Hari and Renvall, 2001, for reviews). Chiefly, the temporal processing hypothesis explicitly claims that phonological decoding (i.e., pseudo word reading) deficits in dyslexics could arise from impairments in sensory processing of visual and auditory dynamic-stimuli (e.g., Geiger et al., 2008; Lallier et al., 2010; Facoetti et al., 2010a,b; Harrar et al., 2014).

The well-known M-D theory of DD is often referred specifically to the visual modality, and it is a comprehensive, albeit controversial account (e.g., Amitay et al., 2002; Sperling et al., 2005, 2006; Olulade et al., 2013). This theory stems from the observation that reading disabled individuals are impaired in the specific visual M-D pathway (e.g., Livingstone et al., 1991; see Stein and Walsh, 1997; Boden and Giaschi, 2007; Vidyasagar and Pammer, 2010; Vidyasagar, 2013; Gori and Facoetti, 2014, 2015; Pammer, 2014, for reviews).

The M-D pathway originates in the ganglion cells of the retina, passes through the $\mathrm{M}$-layer of the lateral geniculate nucleus (LGN), and finally reaches the occipital and parietal cortices (Maunsell and Newsome, 1987). The M-D stream is considered blind to colors, and responds optimally to contrast differences, low spatial frequencies, high temporal frequencies, and motion (Livingstone and Hubel, 1987). The M-D stream mediates the required sensorimotor transformations for visually guided actions (see Goodale and Milner, 1992, for a review).

The M-D stream seems to be impaired in individuals with $\mathrm{DD}$, whereas the other major parallel pathway of the visual system, 
the parvocellular-ventral (P-V) stream, is intact (Stein and Walsh, 1997; Stein, 2001; Boden and Giaschi, 2007; Vidyasagar and Pammer, 2010).

The P-V pathway is characterized by both lower temporal resolution and superior sensitivity to high spatial frequencies, and it is also sensitive to color changes (Livingstone and Hubel, 1987). The P-V stream plays its major role in the perceptual identification of objects (Goodale and Milner, 1992). However, some studies failed to confirm differences in high temporal, low spatial frequency stimulus perceptions, which are thought to rely upon M-D processing, between individuals with DD and controls (e.g., Victor et al., 1993; Johannes et al., 1996; Williams et al., 2003; see Schulte-Körne and Bruder, 2010, for a review).

Importantly, a post mortem study showed that in the brains of individuals with DD the M neurons of the LGN were noticeably smaller than those found in normal readers' brains, while the $\mathrm{P}$ neurons did not differ (Livingstone et al., 1991). This finding was recently buttressed by the first in vivo MRI study (Giraldo-Chica et al., 2015), showing smaller LGN volume in a larger sample of individuals with DD compared to controls.

Gori et al. (2015a) also found the first reported association between a genetic variance (the DCDC2-Intron 2 deletion) and an M-D deficit in both individuals with DD and typical readers. The DCDC2-Intron 2 deletion is a proved DD genetic risk factor (e.g., Meng et al., 2005; Mascheretti et al., 2013; Marino et al., 2014; Riva et al., 2014).

Recently, Gori et al. (2015b) showed that: (i) motion perception was impaired in children with dyslexia in comparison both to age matched and to reading level (RL) controls, that are younger controls who read at the same level as the dyslexics (Goswami, 2003); (ii) pre-reading visual motion perceptionindependently from auditory-phonological skill-predicted future reading development, and; (iii) targeted M-D trainingsnot involving any auditory-phonological stimulation-led to improved reading skill in children and adults with DD. Their findings demonstrate, for the first time, a causal relationship between M-D deficits and DD, virtually closing a 30 years long debate.

It should be noted that the M-D pathway terminates mainly in the posterior parietal cortex, which is highly linked to the prefrontal regions (Mishkin and Ungerleider, 1982; Goodale and Milner, 1992; Merigan and Maunsell, 1993). These cortical regions rapidly control selective attention in humans (e.g., Facoetti and Molteni, 2000; Koyama et al., 2013; Ronconi et al., 2014a, 2016; see Corbetta and Shulman, 2002, 2011; Dosenbach et al., 2008, for reviews). Thus, a weakened or abnormal M-D input to the dorsal-stream could result in a spatial and temporal attention deficit in children and adults with DD (e.g., Brannan and Williams, 1987; Williams et al., 1987; Valdois et al., 1995; Hari et al., 1999; Vidyasagar and Pammer, 1999; Facoetti et al., 2000, 2001, 2005, 2008, 2010b; Iles et al., 2000; Hari et al., 2001; Bosse et al., 2007; Buchholz and Aimola Davies, 2007; Lobier et al., 2014; see Vidyasagar, 1999; Hari and Renvall, 2001; Boden and Giaschi, 2007; Vidyasagar and Pammer, 2010; Stein, 2014, for reviews) and specifically in dyslexics with poor pseudo-word reading ability (Cestnick and Coltheart, 1999; Buchholz and McKone, 2004;
Facoetti et al., 2006, 2010a; Roach and Hogben, 2007; Jones et al., 2008; Ruffino et al., 2010, 2014). Interestingly, the M-D and attentional deficits in individuals with DD were found also in logographic languages such as Chinese (e.g., Zhao et al., 2014; Liu et al., 2015). The visual attentional disorder is now recognized as a core deficit of DD (Franceschini et al., 2012, 2013; Zorzi et al., 2012; see Stein, 2014; Franceschini et al., 2015, for reviews).

\section{VISUAL ILLUSIONS IN DEVELOPMENTAL DYSLEXIA}

The role of visual illusions in unveiling perceptual and attentional deficits in DD was crucial during the last 15 years. For example, Slaghuis et al. (1996) using an apparent motion Ternus display (Ternus, 1938) showed that individuals with DD, both children and adults, presented a significant reduction in Ternus group movement.

Ternus (1938, see Table $\mathbf{1}$ for details) devised an apparent motion stimulus composed of two alternating frames separated by a blank interframe interval (e.g., Alais and Lorenceau, 2002).

The reduced group motion perception in individuals with DD was interpreted as an increase in the duration of visible persistence (Slaghuis et al., 1996), which was consistent with evidence for an M-D pathway disorder in DD (e.g., Livingstone et al., 1991).

Slaghuis and Ryan (1999) also using the Ternus display confirmed the results by Slaghuis et al. (1996) and gave the same explanation in terms of increased visible persistence in children with DD.

Cestnick and Coltheart (1999), employed the Ternus display as well, showing differences between individuals with DD and controls. Their results indicate that the Ternus task performance was related to pseudoword reading but not to exception word reading ability (i.e., phonological DD subtype). These authors provided two alternative interpretations of these findings: (1) pseudoword reading requires a serial left-to-right allocation of visual attention across the letter string being read. The neural systems involved in this attentional process also play a part in responses to the Ternus display; or (2) poor pseudoword reading and abnormal Ternus performance were not directly related: perinatal/neurodevelopmental insult affected the LGN (influencing Ternus performance) and the adjacent medial geniculate nucleus (affecting phonological ability), and the medial geniculate nucleus abnormalities may be more functionally related to poor non-word reading. Davis et al. (2001) confirmed the results found by Cestnick and Coltheart (1999) demonstrating that individuals with DD do genuinely differ from typical readers in their perceptual processing.

Pammer and Lovegrove (2001) convincingly suggested the Ternus display as a proxy able to test the $\mathrm{M}$ pathway functioning in DD. Jones et al. (2008) failed in finding significant differences in the group motion using Ternus display between high functioning adults with DD and a control group. The authors themselves provide one explanation for these results. The $M$ deficit in their specific group of university students, with a high 
TABLE 1 | Descriptions of the visual illusions used in the studies reviewed in this article.

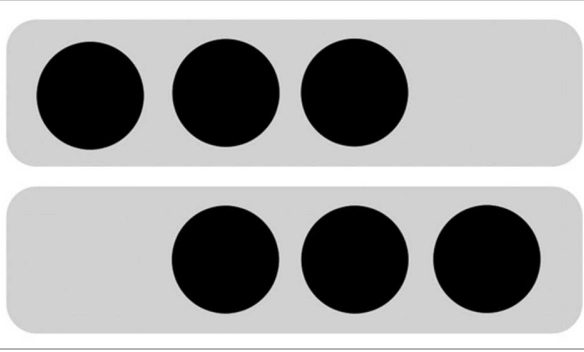

The Ternus display (Ternus, 1938) is composed of two alternating frames (depicted on the left) separated by a blank interframe interval. Each frame contains a horizontal row of three equally spaced elements, with the elements in one frame displaced horizontally relative to those in the other frame by an amount equal to the interelement separation. Because the horizontal displacement and interelement separation are equal, two of the elements in one frame occupy the same locations as two of the elements in the second frame. The apparent motion produced by alternating the frames of the Ternus display is perceptually ambiguous since the visual system is confronted with a motion correspondence problem having several possible solutions (Dawson, 1991).
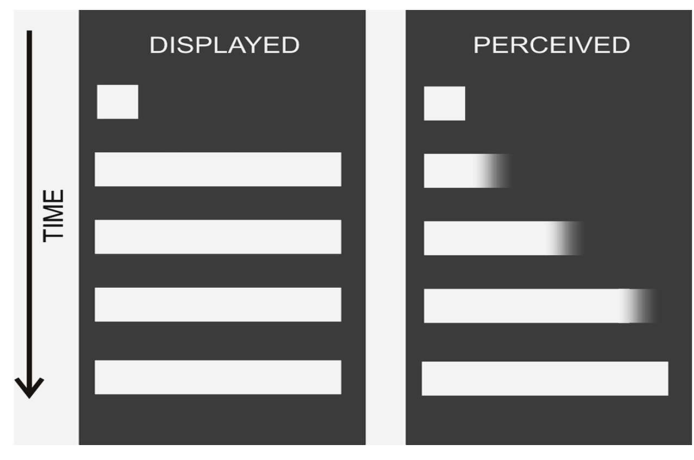

The line motion illusion (Hikosaka et al., 1993) is obtained by the presentation of an attentional cue (a square in the example above) just before the appearance of a stationary line. When a line is displayed by itself, it is perceived to have appeared in a single piece all at once. However, when an attentional cue preceding the line appearance, the line seems to grow from the cued location.

Displayed flickering in counterphase greater than $15 \mathrm{hz}$

Perceived

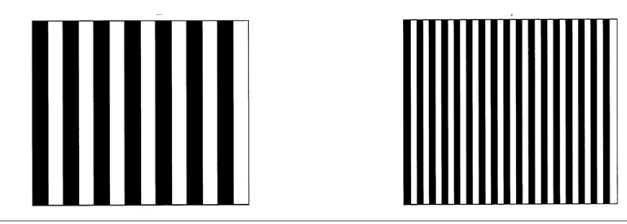

The frequency doubling illusion is a visual illusion that was first described by Kelly (1966). The FD illusion appears to be dependent on the spatial and temporal frequency of a flickering grating. When a grating with a spatial frequency of $0.1-4 \mathrm{c} / \mathrm{deg}$ is flickering in counterphase, faster than $15 \mathrm{~Hz}$, the viewer perceives a grating with double the physical spatial frequency.

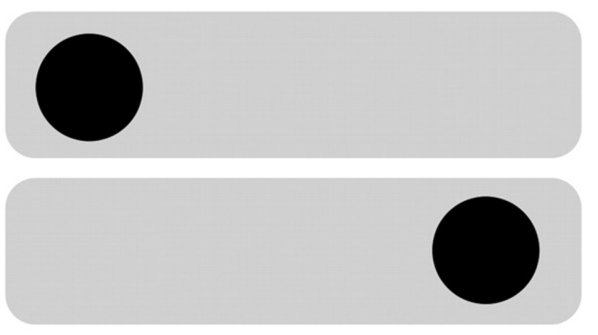

The visual stream segregation (Bregman and Achim, 1973) is an apparent motion display based on the classical $\beta$ movement. The optimal apparent movement (or $\beta$ ) was known already in the XIX century, and it resembles real movement. Apparent motion $\beta$ can be perceived when two spatially segregated visual stimuli are presented in succession [although the disappearance of the first element seems not to be necessary to the motion perception as showed by Gori et al. (2010b)].

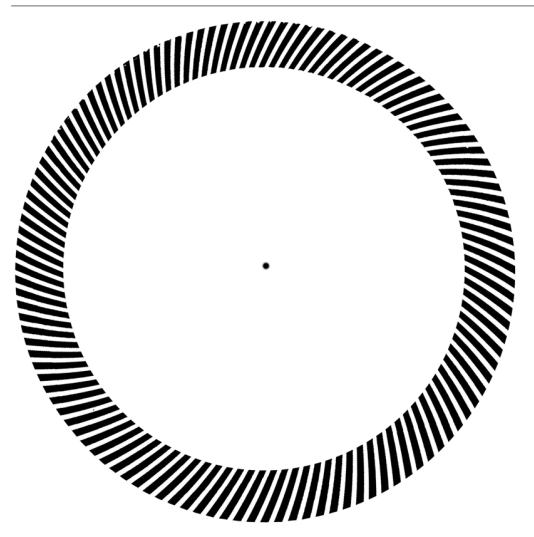

The rotating tilted lines illusion (Gori and Hamburger, 2006), is the simplest pattern able to trigger illusory rotation in presence of only radial expansion motion on the retina. Approaching this pattern, maintaining fixation on the center spot the circle of lines appears to rotate. The misperception of motion seems to be caused by the aperture problem (Wallach, 1935) faced by the small receptive fields of V1 (Gori and Yazdanbakhsh, 2008; Yazdanbakhsh and Gori, 2008). 


\section{TABLE 1 | Continued}

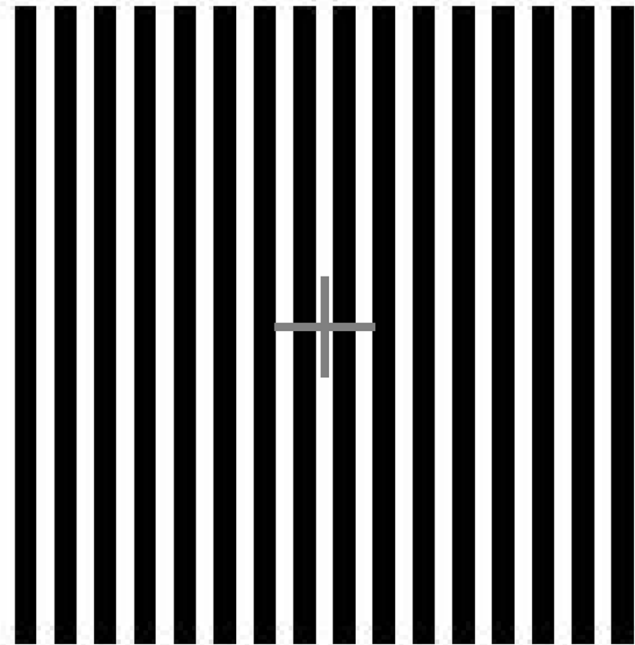

The accordion grating illusion (Gori et al., 2011, 2013) consist in a square-wave grating which exhibits two distinct illusory effects. Approaching this pattern, it appears: (i) to expand only perpendicularly to the stripes while (ii) the rigidity of the stripes is lost and a curvature is experienced. The origin of this illusory effect seems to rely on the aperture problem (introducing the concept of three-dimensional aperture problem; Yazdanbakhsh and Gori, 2011), and on the competition between motion signals originating from two motion-processing units in $\mathrm{V} 1$.
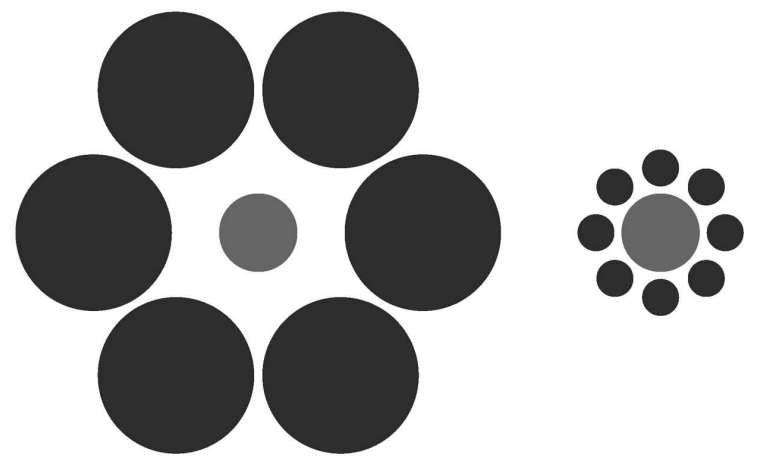

The Ebbinghaus illusion (Ebbinghaus, 1902) is a size illusion composed by two circles of identical size that are placed near to each other, while one is surrounded by large circles the other is surrounded by small circles. The central circle surrounded by large circles appears smaller than the one surrounded by small circles.

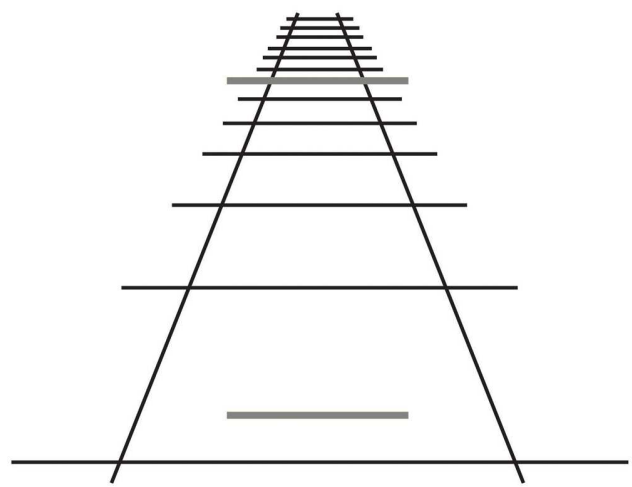

The Ponzo illusion (Ponzo, 1911) is characterized by two identical lines (light gray horizontal lines in the example above) across a pair of converging lines that could resemble railway tracks. The upper line is normally perceived longer probably because the converging lines are automatically interpreted as depth cues by the visual system. Consequently, the upper line is considered by the visual system as it was farther away, and then perceived longer: a further object would have to be bigger than a nearer one when both are producing two retinal images of the same size.

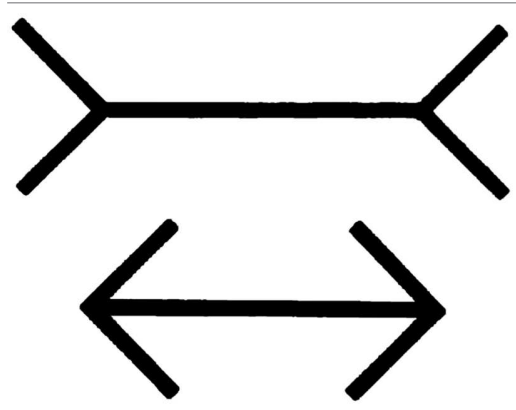

The Müller-Lyer illusion (Müller-Lyer, 1889) is commonly represented as two lines of equal length with arrow-like terminators called fins. One line has the fins pointing inward and it is perceived to be longer than the line with the fins pointing outward. 
TABLE 1 | Continued

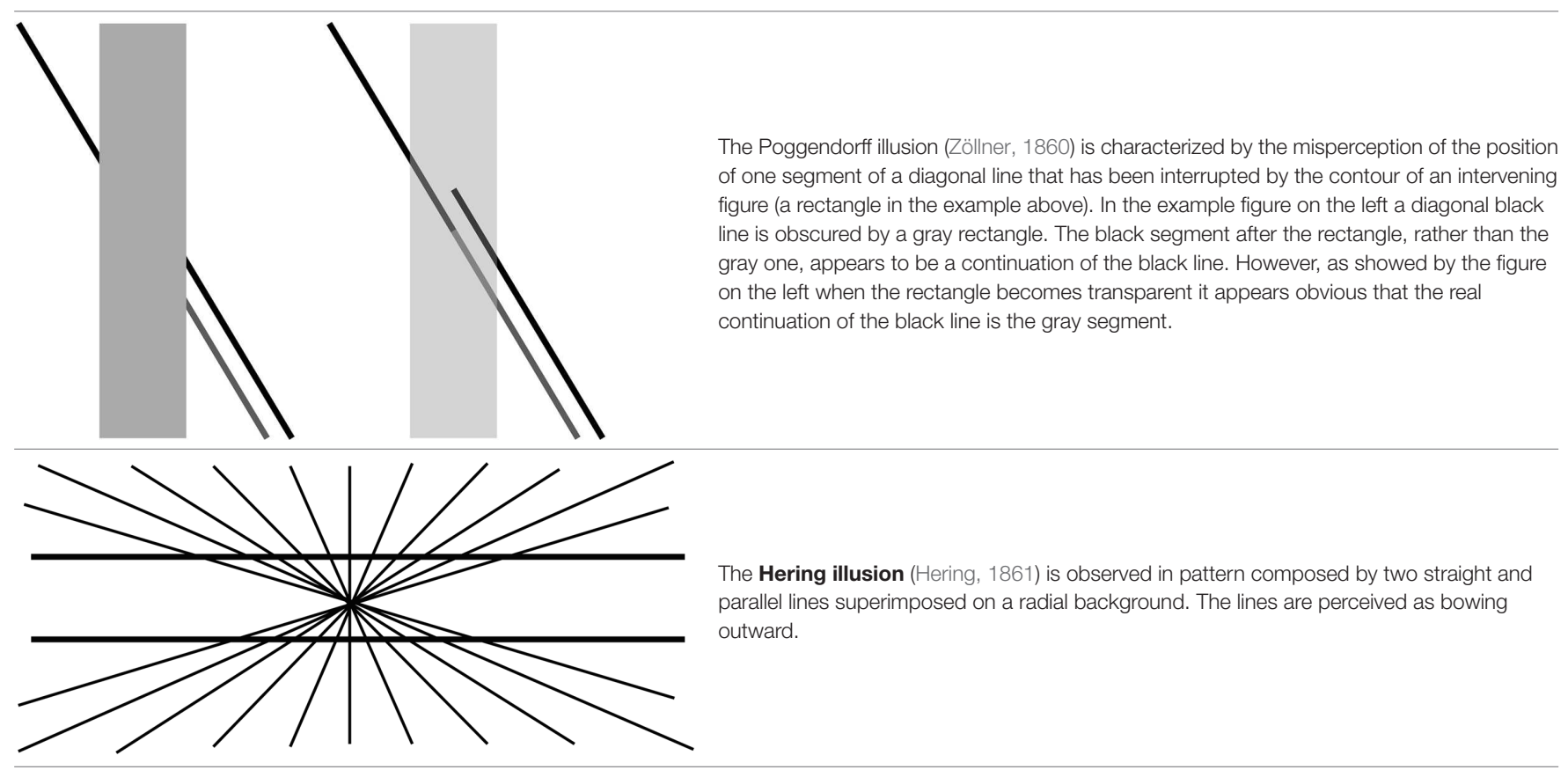

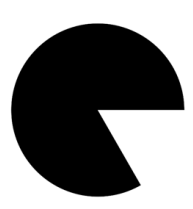
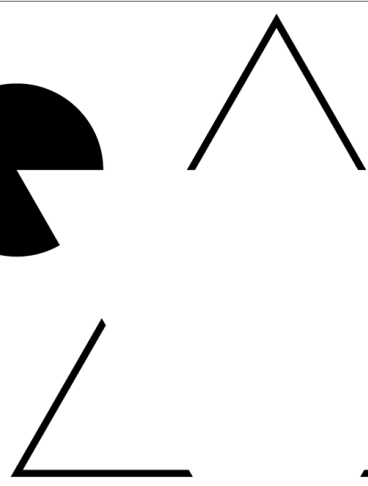
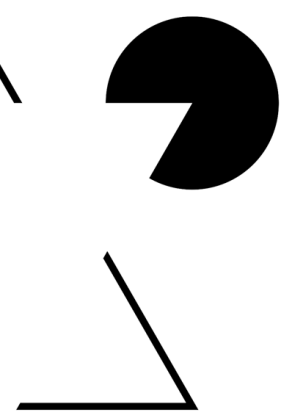

The Kanizsa triangle (Kanizsa, 1955) is the most famous pattern exhibiting illusory contour. This pattern is composed by trigger Pac-Man-shaped aligned. The Kanizsa pattern evokes the percept of a triangle, defined by a sharp illusory contour although no physical triangle is present in the stimulus. Moreover, the illusory triangle appears brighter than a background of the same luminance. Finally, the illusory triangle is perceived closer to the observer than the inducers.
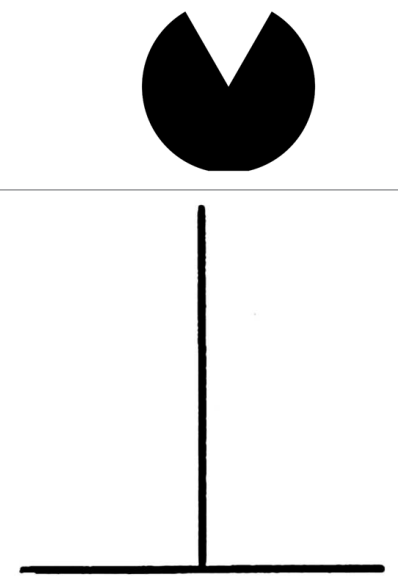

The vertical-horizontal illusion (Fick, 1851) is commonly represented by an inverted T with equal-length vertical and horizontal components. Observers reported that the vertical line appears significantly longer than the horizontal one. 

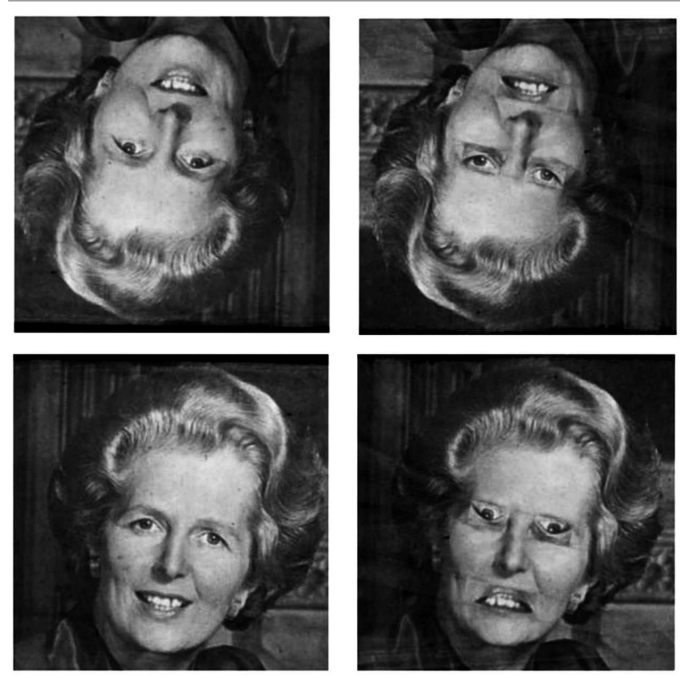

Thatcher Illusion (Thompson, 1980) is a phenomenon in which it becomes more difficult to detect local feature changes, like eyes or mouth, in an upside-down face (upper part of the figure), despite such changes would be easy to spot in an upright face (lower part of the figure).

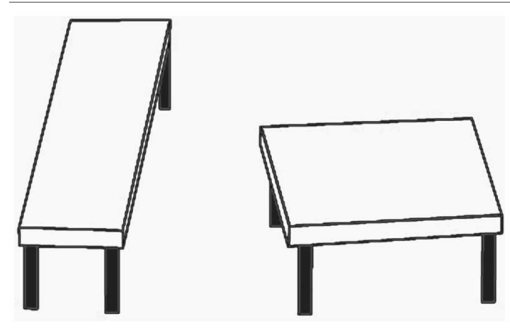

The Shepard (1981) Tables illusion consists in misperceiving the shape of a parallelogram in the presence of depth cues. It is characterized by two tables, where one table seems longer and thinner, even though it is actually identical to the other but simply rotated.

degree of compensation, is so mild that difficulty only arises when $\mathrm{M}$ input is required for the direction of sequential attention (Vidyasagar, 1999, 2013; Facoetti, 2012). Moreover, in the Jones et al. (2008) study, the group with DD was unselected and no subtyping was done. Cestnick and Coltheart (1999) found differences in the Ternus display performance specifically in the phonological DD subtype.

Pammer and Wheatley (2001) showed that individuals with $\mathrm{DD}$ are less sensitive to the detection of the frequency doubling (FD) illusion pattern than normal readers, supporting a low-level deficit in the M-D pathway. The FD illusion (see Table 1 for details) was explained by Kelly (1981) in terms of the full wave rectification carried out by the visual system. Such rectification is found in $\mathrm{M}(\mathrm{y})$-cells of the primate retina (Benardete et al., 1992) and LGN (Kaplan and Shapley, 1982; Marrocco et al., 1982). It is therefore suggested, that responses from the $\mathrm{M}(\mathrm{y})$-cells underlie perception of the FD illusion (see Maddess et al., 1992, for a detailed discussion regarding the relationship between $\mathrm{M}(\mathrm{y})$-cells and frequency doubling).

Buchholz and McKone (2004) confirmed the results of Pammer and Wheatley (2001) showing deficits in both $\mathrm{M}$ pathway (FD illusion) and attentional tasks. These deficits cannot be explained by differences in concentration lapses, eye movements or reaction times between individuals with DD and controls.

Pammer et al. (2004) showed that a poor performance in the FD illusion task was associated with a lower ability to read a word inside the text, which could suggest a dysfunctional attentional focus in individuals with DD.

Kevan and Pammer (2008) demonstrated that children at familial risk for DD already show a higher threshold for the FD illusion even at pre-reading stage. Importantly, in their longitudinal study (Kevan and Pammer, 2009), the threshold for the FD illusion at the pre-reading stage predicts future reading skills, suggesting a causal role of the M-D deficit in DD.

Gori et al. (2014) recently demonstrated that children with DD showed a lower performance in the FD illusion task not only in comparison with an age matched control group, but also with an $\mathrm{RL}$ control group. The use of the RL control can be a first step in research aimed at delineating the causal factors in reading disabilities.

In addition, Steinman et al. (1998) employed the linemotion illusion (Hikosaka et al., 1993) to show how the spatial distribution of attention (e.g., Facoetti and Molteni, 2001) which is dominated by the M input - differs between individuals with DD and typical readers.

The line motion illusion is obtained by the presentation of an attentional cue just before the appearance of a stationary line (see Table 1 for details). This stimulus revealed the connection between the M-D pathway and the attentional deficit in DD (Steinman et al., 1998). Recently, Hamm et al. (2014) showed, using fMRI, that the pattern of brain activation during a motion direction task while observing the line motion illusion was very consistent with the attentional gradient model. These results confirmed that this stimulus is a good 
proxy for measuring the attentional abilities of individuals with DD.

Lallier et al. (2009) employed an apparent motion display coined by Bregman and Achim (1973) the "visual stream segregation". The "visual stream segregation" (Bregman and Achim, 1973) is an apparent motion display based on the classical $\beta$ movement (see Table 1 for details). The illusion persists even when the stimuli are widely separated, a phenomenon called "long-range apparent motion" (Braddick, 1980; Maloney et al., 2005; Schiller and Carvey, 2006). In order to respond to apparent motion, neurons have to integrate information over a large part of visual space, spanning at least the distance between the two inducing stimuli. Several studies have shown that MT in the macaque and other primates and its human homolog, the MT/V5 complex (hMT/V5+), respond to stimulus conditions that induce apparent motion (e.g., Mikami, 1991). In contrast, receptive-field sizes in early visual areas and, in particular, the primary visual cortex (V1) are too small to account for long-range interactions between stimuli. The fact that one actually observes spatially resolved movement between the inducing stimuli in apparent motion suggests that there could be a filling-in process in early visual areas that is driven by feedback from extrastriate regions with larger receptivefield sizes. In particular, back-projections from hMT/V5+ have been shown to be relevant for perception of motion and apparent motion (e.g., Pascual-Leone and Walsh, 2001). Muckli et al. (2005) proved that the activity in V1 changes as a function of the subjectively perceived motion trace. Sterzer et al. (2006) showed, using fMRI, how the hMT/V5+ feedback mediated the activation of $\mathrm{V} 1$ in the presence of apparent motion.

The visual stream segregation was used in conjunction with an auditory stream segregation to assess the "sluggish attentional shifting" (SAS) hypothesis (Lallier et al., 2009) suggested by Hari and Renvall (2001). This theory argues that individuals with DD would show attentional deficit, through SAS, in all sensory modalities. The amodality assumption of the SAS theory was never directly assessed before in the same group of individuals with DD using similar paradigms in both the visual and auditory modalities. Lallier et al. (2009) showed a deficit in both auditory and visual modality in individuals with DD. These results supported the view that the multisensory SAS hypothesis. Lallier et al. (2010) confirmed these results adding also evoked related potentials (ERPs) evidence.

Gori et al. (2015a) showed that children with DD presented a lower performance also in tasks specifically tapping the $\mathrm{D}$ portion of the M-D pathway in comparison with both age controls and RL controls. Moreover, Gori et al. (2015a) reported, for the first time, an association between a genetic variance (a deletion in intron 2 of the DCDC2 gene), and an M-D deficit in individuals with and without DD. In order to obtain these results, two motion illusions were employed: the rotating tilted lines illusion (RTLI) (Gori and Hamburger, 2006) and the accordion grating illusion (AGI) (Gori et al., 2011, 2013).

The RTLI, is the simplest pattern able to trigger illusory rotation in the presence of only radial expansion motion on the retina (see Table 1 for details). The illusory effect appears to be strongly reduced or even to disappear with isoluminant colors (Hamburger, 2012).

The second motion illusion employed by Gori et al. (2015a) was the AGI consisting in a square-wave grating which exhibits two distinct illusory effects (see Table 1 for details). The V5/MT, which is a core, neural station of the M-D pathway, also processes the illusory motion perception (Ruzzoli et al., 2011). Consequently, the RTLI and the AGI represent appropriate candidates for testing the functioning of this visual pathway. The choice of testing illusory motion was not only interesting for itself, but it also provided some advantages in comparison to testing the real motion perception. The main technical advantage was that the illusory motion required more contrast than real motion to be perceived, which provided a larger window to vary the independent variable. The direct consequence was having a more sensitive instrument to test the M-D pathway functionality. Moreover, most of the evidence for the visual D deficit in DD has derived from studies of coherent dot motion perception (see Stein, 2014, for a recent review). However, the impairment in the coherent dot motion task was only found in the presence of high external noise (Sperling et al., 2006). The illusory motion tasks were the first able to measure the more dorsal portion of the M-D pathway being clearly independent from any noise exclusion mechanism. The RTLI was also used to show the M-D functioning improvement after action video game training in children with DD (Gori et al., 2015b).

Finally, although it is out of the scope of this review on visual illusions, it is interesting to mention that auditory illusions also played an important role in the study of DD (e.g., Hari and Kiesila, 1996; Helenius et al., 1999; Lallier et al., 2009, 2010).

In summary, visual illusions played a crucial role in the study of DD, and it is probably only the starting point of a successful long collaboration between scientists studying this neurodevelopmental disorder and researchers in vision sciences. In particular, the above described visual illusions clearly played a prominent role in providing important evidence for the M-D theory and the attentional deficits in DD. Interestingly, the results obtained by the reviewed visual illusions not only helped in showing an association between perceptual and attentional deficits and DD, but also provided often the first evidence of a causal role of these cognitive deficits on the emergence of DD (see Table 2 for a summary of reviewed studies).

\section{VISUAL DEFICIT IN AUTISM SPECTRUM DISORDER}

Autism spectrum disorder (ASD) is a pervasive developmental condition characterized by abnormalities in communication, social interaction, and presence of markedly restricted interests and stereotyped behaviors (American Psychiatric Association Task Force on DSM-IV, 1994).

Although the dysfunctions in social cognition and communication are typically considered the "core" deficits in ASD individuals, a growing amount of evidence consistently reports abnormalities in low-level visual perception and attention 
TABLE 2 | Overview of the published articles investigating visual illusions sensitivity in developmental dyslexia (DD).

\begin{tabular}{|c|c|c|}
\hline Reference & Visual Illusion & Main results (i.e., illusion sensitivity) \\
\hline Slaghuis et al., 1996 & Apparent motion Ternus display & DD $<$ Controls in perceived group motion \\
\hline Steinman et al., 1998 & Line-motion illusion & DD $<$ Controls \\
\hline Slaghuis and Ryan, 1999 & Apparent motion Ternus display & DD (only mixed subtype of dyslexia) < Controls in perceived group motion \\
\hline Cestnick and Coltheart, 1999 & Apparent motion Ternus display & DD (only phonological subtype of dyslexia) < Controls in perceived group motion \\
\hline Davis et al., 2001 & Apparent motion Ternus display & DD $<$ Controls n perceived group motion \\
\hline Pammer and Wheatley, 2001 & Frequency doubling illusion & $\mathrm{DD}<$ Controls \\
\hline Buchholz and McKone, 2004 & Frequency doubling illusion & DD $<$ Controls \\
\hline Jones et al., 2008 & Apparent motion Ternus display & $\mathrm{DD}=$ Controls \\
\hline Kevan and Pammer, 2008 & Frequency doubling illusion & Pre-readers at familial risk for DD $<$ Pre-readers not at risk \\
\hline Kevan and Pammer, 2009 & Frequency doubling illusion & Future poor readers $<$ Future typical readers \\
\hline Lallier et al., 2009 & Visual stream segregation & DD $<$ Controls \\
\hline Lallier et al., 2010 & Visual stream segregation & $\mathrm{DD}<$ Controls \\
\hline Gori et al., 2014 & Frequency doubling illusion & DD (only children) < in comparison to both chronological-age and reading-level Controls \\
\hline Gori et al., 2015a & $\begin{array}{l}\text { Rotating tilted lines illusion, } \\
\text { Accordion grating illusion }\end{array}$ & DD (only children) < in comparison to both chronological-age and reading-level Controls \\
\hline
\end{tabular}

(e.g., Happé, 1999; Dakin and Frith, 2005; Mottron et al., 2006; Simmons et al., 2009, for reviews, but see Grubb et al., 2013a,b). The idea that atypical visual processing can account for the core deficits of the disorder is one of the most intriguing aspects of the current research in autism (e.g., Vlamings et al., 2010; Mazer, 2011; Ronconi et al., 2012, 2013a,b; Manning et al., 2015).

According to the neuroconstructivist approach (see KarmiloffSmith, 1998; Johnson, 2011, for reviews) early abnormalities in low-level perception and attention could cause the typical developmental trajectories to deviate and produce impairments in high-level cognitive domains (e.g., Mundy, 2003; Elsabbagh and Johnson, 2010; Franceschini et al., 2012; Ronconi et al., 2014b). Attentional impairments are probably the most consistently reported neurocognitive deficit in infants and children with ASD (e.g., Elsabbagh et al., 2013; see Allen and Courchesne, 2001; Ames and Fletcher-Watson, 2010; Sacrey et al., 2014, for reviews).

The attention spotlight is not only oriented in a specific location, but also has to be adjusted in its size (Eriksen and St. James, 1986; Turatto et al., 2000). This ability allows one to process visual stimuli from a narrow (zoom-in) or a broad visual region (zoom-out) (e.g., Facoetti and Molteni, 2000; Facoetti, 2001). Lovaas and Schreibman (1971) showed that children with autism responded to a restricted range of environmental stimuli, suggesting that their attention was excessively focused. The authors explained these findings in terms of "stimulus over-selectivity". More recently, this idea was corroborated by a prolonged zoom-in and sluggish zoomout attentional mechanism (Ronconi et al., 2012, 2013b). This abnormal attentional focusing is probably linked to dysfunctional top-down feedback from the fronto-parietal network to the early visual areas. The attentional zoom-out deficit could contribute to the atypical visual perception associated to individuals with ASD, which, in turn, could have consequences in their social-communicative development (Mann and Walker, 2003; Ronconi et al., 2012, 2013b; Robertson et al., 2013; Song et al., 2015).
Stimulus over-selectivity can also be coupled with a strong resolution for the details. Compared to typically developing peers, individuals affected by ASD manifest better performance in local element discrimination involving static visual stimuli, as in visual search tasks (e.g., O'Riordan et al., 2001; Almeida et al., 2010; Gliga et al., 2015), in the embedded figure test (e.g., Jolliffe and Baron-Cohen, 1997; Manjaly et al., 2007) and in visual crowding (Baldassi et al., 2009). An enhanced visual processing of detailed information preference in ASD was also demonstrated with electrophysiological recordings (Pei et al., 2009, 2014; Vlamings et al., 2010).

The local bias in autism seems to also occur for dynamic visual information (Chen et al., 2012). However, it is still unclear whether the perceptual bias for details (i.e., local processing) over global elements (i.e., global processing) is at the expense of the understanding of the visual scene (e.g., Chouinard et al., 2013).

\section{VISUAL ILLUSION IN AUTISM SPECTRUM DISORDER}

Visual illusions are ideal for examining whether or not weak central coherence theory can explain perceptual processing in ASD (Frith and Happé, 1994; Happé and Frith, 2006; Chouinard et al., 2013). Central coherence is defined as the tendency to process incoming information in its context often with a cost regarding memory for details (Happé, 1999).

The weak central coherence theory suggests that problems with global processing in individuals with ASD can allow them to see the local elements in a very accurate way.

The weak central coherence theory has no explicit neurobiological counterpart (Caron et al., 2006). However, Milne et al. (2002) and Greenaway and Plaisted (2005) suggested that a deficit in perceiving the global aspect of visual stimuli could derive from a dysfunction of the M-D pathway. This hypothesis appears controversial and it has been criticized by 
several studies (Mottron et al., 2003, 2006; Bertone et al., 2005; Ronconi et al., 2012).

Based on the weak central coherence theory, ASD could be less susceptible to the visual illusions that are based on global indices or integration of local elements. During the last 15 years, several studies employed visual illusions to examine weak central coherence theory and, more in general, the perception peculiarities observed in individuals with ASD.

To our knowledge, Happé (1996) was the first to connect the world of visual illusions with the research on ASD. Her study opened a debate that is still now at the center of ASD research. Happé (1996) investigated the response to six geometrical illusions (see Ninio, 2014, for a recent review of this category of illusions) in individuals with ASD: the Ebbinghaus illusion (Ebbinghaus, 1902, also known as Titchener circles, Titchener, 1901), Ponzo Illusion (Ponzo, 1911), Müller-Lyer illusion (Müller-Lyer, 1889), Poggendorff illusion (Zöllner, 1860); Hering illusion (Hering, 1861), and the Kanizsa triangle (Kanizsa, 1955). Three groups of individuals were part of this study: a group with ASD, another one with learning difficulties and a control group of typical developing participants. The illusory patterns were standard two-dimensional (2-D) black and white line drawings, or three-dimensional (3-D) appearance patterns obtained by adding colored lines. The individuals with autism were less likely to succumb to the 2-D illusory patterns than the other groups, and were less aided by the 3-D control condition. Happé (1996) concluded that children with ASD were significantly less sensitive than control children to visual illusions. These results were interpreted in favor of weak central coherence in ASD.

All the visual illusions employed in the Happé (1996) study are clearly characterized by global information that produces illusory percepts. The Ebbinghaus illusion (Titchener, 1901; Ebbinghaus, 1902, see Table 1 for details) produced a large number of papers (e.g., Weintraub, 1979; McCarthy et al., 2013), showing how relevant this pattern is in vision sciences.

The Ponzo illusion (Ponzo, 1911), also produced a large amount of literature (e.g., Fisher, 1968; Parks, 2013). Several studies and different interpretations were published on the Müller-Lyer illusion (Müller-Lyer, 1889, see Table 1 for details) too (e.g., Wickelgren, 1965; de Brouwer et al., 2014). Plewan et al. (2012) using fMRI showed that the lateral occipital cortex and right superior parietal cortex were associated with illusion strength.

The Poggendorff illusion (see Table 1 for details) was discovered by Poggendorff during the observation of the figure published by Zöllner (1860), while being the editor of the journal that first published the now very popular image. Several studies and different interpretations have since been published on this phenomenon (e.g., Green and Hoyle, 1963; Daneyko et al., 2011).

The Hering illusion (Hering, 1861, see Table $\mathbf{1}$ for details) is also a classical illusion that has produced several studies and different interpretations (e.g., Holt-Hansen, 1973; Hamburger et al., 2007).

Finally, the Kanizsa triangle (Kanizsa, 1955) is the most famous pattern exhibiting illusory contour. The illusory contours inspired a large amount of literature (e.g., Sarti et al., 2000; Bulf et al., 2009). Neurons in area V2 and even V1 respond to the cues that induce illusory contours in human observers much in the same way as to real contours (e.g., Heitger et al., 1998; Spillmann, 2009). This is surprising as the receptive field fell in-between the inducers with no access to the surround, showing the limitation of the classical receptive field model (e.g., Peterhans and der Heydt, 1989; Soriano et al., 1996).

Hirsch et al. (1995), using fMRI, showed that specific brain regions were activated in extrastriate cortex only in presence of illusory contours. These unique regions were found primarily in the right hemisphere.

Later, Ropar and Mitchell (1999, 2001) investigated the following visual illusions in individuals with ASD: Ebbinghaus (Ebbinghaus, 1902), Ponzo (Ponzo, 1911), Müller-Lyer illusion (Müller-Lyer, 1889), and the vertical-horizontal illusion (Avery and Day, 1969). These authors - using a different control condition - did not find any significant difference in illusion perceptions between individuals with ASD and controls, arguing against the weak central coherence theory. The control stimuli were the same illusory patterns from which the global elements triggering the illusion were eliminated.

Besides the already described illusions, Ropar and Mitchell $(1999,2001)$ also used the vertical-horizontal illusion (Avery and Day, 1969, see Table 1 for details).

This classical illusion is no exception in producing a large number of studies (e.g., Künnapas, 1955; Mikellidou and Thompson, 2013), but one of the most complete investigations seems to be the study by Mamassian and de Montalembert (2010), who proposed a model able to quantitatively describe the illusory effect.

Hoy et al. (2004) employed the same six visual illusions used in the study by Happé (1996). No difference in the illusory perception between individuals with ASD and typically developed controls was found.

In the same year, Rouse et al. (2004) showed no differences in the illusory perception of the Thatcher Illusion (Thompson, 1980, see Table 1 for details) between individuals with ASD and controls. The authors concluded that children with ASD are able to compute second-order configural features in faces and they do not show differences in face processing, relative to controls.

Although not a classical illusion, the Thatcher Illusion captured a large interest in the vision sciences community, as showed by the large amount of literature that refers to it (e.g., Valentine and Bruce, 1985; Mestry et al., 2014).

Using fMRI, Psalta et al. (2014) found a peculiar involvement of the superior temporal sulcus - a region known to be linked to the facial expressions processing - only when the face of the Thatcher Illusion was upright.

Brown et al. (2005), recording with the EEG, showed gamma band abnormalities in adolescents with ASD while observing the Kanizsa triangle. However, no difference between groups in the report of the participants was observed. Simmons et al. (2009) suggested that this difference in the gamma band could be an artifact due to eye movements.

Bölte et al. (2007) employed the same six visual illusions used in the study by Happé (1996), but in a sample composed of individuals with high-functioning autism (HFA) and found that 
children with HFA showed a significantly less sensitivity to these visual illusions.

In the same year, Stroganova et al. (2007) found differences in ERPs between children with ASD and controls watching illusory contours (Kanizsa, 1955).

Later, Milne and Scope (2008) tested perception of illusory contours in children with ASD using a paradigm that requires participants to make a forced choice about the dimensions of a shape defined by illusory contours. There were no significant differences between the performance of children with ASD and either of the two control groups (a group of children with special educational needs and another one composed of typically developing children).

Walter et al. (2009) investigated individuals with autistic traits instead of examining susceptibility to visual illusions directly in a population with ASD, in which it is more difficult to acquire precise measurements of perception. These authors employed the Ponzo Illusion (Ponzo, 1911) and the Poggendorff illusion (Zöllner, 1860). A significant relationship was found between autistic traits and susceptibility to the tested illusions, supporting the idea that perception in autism is heavily weighted toward local features relative to typically developed individuals.

Mitchell et al. (2010) compared individuals with ASD who had IQs in the normal range against matched controls in their susceptibility to the Shepard's (1981) illusion (see Table $\mathbf{1}$ for details). Both groups succumbed to the illusion. However, individuals with autism were less susceptible to the illusion than typically developing controls. The authors interpreted these results as attenuated top-down influences in individuals with ASD.

Chouinard et al. (2013) also investigated individuals with autistic traits. Given that ASD is commonly associated with comorbid disorders, a psychophysical study on visual illusions in the general population is conceivably more likely to be reproducible (Chouinard et al., 2013). These authors employed the Ebbinghaus (Ebbinghaus, 1902), the Ponzo (Ponzo, 1911), and Müller-Lyer illusions (Müller-Lyer, 1889). Their findings confirm that the cognitive operations underlying global processing in the Müller-Lyer illusion are peculiar in comparison with other illusions and showed that this specific type of global processing may be affected in ASD.

In summary, visual illusions have played an important role in the study of ASD, however, in contrast to the studies involving visual illusions and $\mathrm{DD}$, the results in ASD seem to be more controversial, withsome studies presenting opposite results (see following chapter for possible reasons for these outcomes). These findings should not discourage future researches from employing visual illusions to investigate atypical perception in ASD. On the contrary, it should motivate scientists to find creative solutions to reduce discrepancy. For example, the suggestion by Chouinard et al. (2013) to investigate individuals with autistic traits could be the way to follow in the future.

In sum, illusory effects driven by contextual cues (global information) were the illusions employed in almost the totality of the ASD studies reported here. This choice was the result of testing the weak central coherence hypothesis in ASD, however, this can be viewed as an opportunity for future research to employ completely different kinds of visual illusions to further investigate the peculiar way in which individuals with ASD perceptually characterize the world (see Table 3 for a summary of reviewed studies).

\section{CONFLICTING FINDINGS ABOUT VISUAL ILLUSIONS IN AUTISM SPECTRUM DISORDER}

The mixed results found for the weak central coherence hypothesis in ASD when examined by the visual illusions could be due to several factors.

The lack of significant difference observed between the ASD group and controls, such as those by Ropar and Mitchell (1999, 2001), could be due to differences in the procedure compared to Happés (1996) original study. Happé and Frith (2006) pointed out that Ropar and Mitchell $(1999,2001)$ did not used the 3D control stimuli originally employed by Happé (1996). This control, according to Happé and Frith (2006) could be helpful in disambiguating the conflicting results.

TABLE 3 | Overview of the published articles investigating visual illusions sensitivity in autism spectrum disorder (ASD).

\begin{tabular}{|c|c|c|}
\hline Reference & Visual illusion & Main results (i.e., illusion sensitivity) \\
\hline Happé, 1996 & Ebbinghaus, Ponzo, Müller-Lyer, Poggendorff, Hering illusions, and Kanizsa triangle & $\begin{array}{l}\text { ASD < in comparison to both Controls and } \\
\text { children with learning difficulties }\end{array}$ \\
\hline Ropar and Mitchell, 1999 & Ebbinghaus, Ponzo, Müller-Lyer, and vertical-horizontal illusions & $\begin{array}{l}\mathrm{ASD}=\text { in comparison to both Controls and } \\
\text { children with moderate learning difficulties }\end{array}$ \\
\hline Ropar and Mitchell, 2001 & Ebbinghaus, Ponzo, Müller-Lyer, and vertical-horizontal illusions & $\begin{array}{l}\text { ASD = in comparison to both Controls and } \\
\text { children with moderate learning difficulties }\end{array}$ \\
\hline Hoy et al., 2004 & Ebbinghaus, Ponzo, Müller-Lyer, Poggendorff, Hering illusions, and Kanizsa triangle & ASD $=$ Controls \\
\hline Rouse et al., 2004 & Thatcher & ASD $=$ Controls \\
\hline Bölte et al., 2007 & Ebbinghaus, Ponzo, Müller-Lyer, Poggendorff, Hering illusions, and Kanizsa triangle & High-functioning autism $(\mathrm{HFA})<$ Controls \\
\hline Stroganova et al., 2007 & Illusory contours (ERP data) & ASD $<$ Controls \\
\hline Milne and Scope, 2008 & Illusory contours & ASD $=$ Controls \\
\hline Walter et al., 2009 & Ponzo and the Poggendorff & ASD $<$ Controls \\
\hline Mitchell et al., 2010 & Shepard illusion & ASD $<$ Controls \\
\hline Chouinard et al., 2013 & Ebbinghaus, the Ponzo Illusion, and the Müller-Lyer illusion. & ASD $<$ Controls for the Müller-Lyer illusion \\
\hline
\end{tabular}


Moreover, Happé and Frith (2006) suggested that a possible explanation for conflicting findings could be related to the information provided to the individuals with ASD. Participants with ASD made misjudgments similar to those observed in typically developed individuals when asked, for example, whether two lines of an illusion "looked the same length", but were much more accurate than controls when asked whether the two lines “were the same length" (Happé and Frith, 2006).

Later, Walter et al. (2009) suggested that a real difference in susceptibility to visual illusions between individual with ASD and controls might have been obscured by the circumstances under which the studies were performed and the various types of control populations adopted across studies. An important difficulty is dealing with differences in mental age between the groups. Typically, selecting a mentally age matched control group for comparison with an ASD group solves this problem. However, this solution often results in a difference in chronological age between the groups. This difference could potentially be a problem while measuring illusion susceptibilities (Walter et al., 2009), since it is known that susceptibilities to visual illusion can be modulated by age (e.g., Billino et al., 2009). Some authors have suggested that visual illusion susceptibility reaches an adultlike level between the ages of 6 years (e.g., Weintraub, 1979; Zanuttini, 1996) and 15 years old (e.g., Brosvic et al., 2002; Bondarko and Semenov, 2004). On the other hand, some authors showed that this susceptibility changes throughout the life span, and it also depends from the specific pattern employed (e.g., Coren and Girgus, 1978; Billino et al., 2009). Another option could be to compare a group of individuals with ASD to a control group matched for chronological age, but this would introduce a confound, if illusion susceptibility is instead correlated to mental age (Walter et al., 2009).

Another potential source of conflicting findings can be the heterogeneity of the ASD group itself. This would be particularly problematic when the ASD group contains individuals across the autistic spectrum (Walter et al., 2009). Moreover, even in the presence of similar diagnoses, the heterogeneity in cognitive abilities and severity of impairments recorded among individuals with ASD often remains great (Baron-Cohen et al., 2003; Belmonte et al., 2004). The individual differences in the ASD group are all the more magnified when comorbid disorders are present (Billstedt, 2000). Considering that the samples of individuals with ASD in the above reported studies are always relatively small, this within-group heterogeneity could sometimes potentially obscure a real difference between groups (Walter et al., 2009).

Also Chouinard et al. (2013), highlighted the heterogeneous nature of ASD (Billstedt, 2000) as a possible cause of conflicting results in studies investigating visual illusions in this clinical population.

Moreover, Chouinard et al. (2013) stressed that there are a several difficulties in carrying out well-controlled visual psychophysical experiments in individuals with ASD, such as variability in compliance, instruction comprehension, and perseverative behaviors.

In addition, the sluggish zoom-out of attentional focus showed in individuals with ASD (Mann and Walker, 2003; Ronconi et al., 2012, 2013b; Robertson et al., 2013; Song et al., 2015) could be another source of conflicting results. Different sizes and durations of the illusory stimuli might change results radically due to the difficulty in zooming out characterized in individuals with ASD.

Both, Walter et al. (2009) and Chouinard et al. (2013) proposed comparing measures of autistic tendencies to individual differences in visuospatial processing ability within a typically developing population.

Simmons et al. (2009) agreed that this methodology can be an alternative way to study the impact of autistic traits on visuospatial processing, without introducing confounds like age differences, comorbidity, and variable symptoms. The use of continuous measures instead of dichotic classification ("ASD" or "typical") as a means of quantifying particular autistic traits, allows correlations between performance on visuospatial tasks and trait strengths to be measured (Walter et al., 2009).

Moreover, it is possible to study the effects of a single autistic trait rather than treating all traits associated with ASD as a whole (Walter et al., 2009; Ronconi et al., 2014b). An additional advantage of this continuous-trait approach is the possibility of easily recruiting much larger samples; this option allows for much greater data collection than when limiting recruitment those diagnosed with ASD. Interestingly, both studies employing this methodology (Walter et al., 2009; Chouinard et al., 2013) reported that high autistic traits are related to less susceptibility to some visual illusions.

However, as noticed by Chouinard et al. (2013), the extent to which these results can generalize to the individuals with ASD may need further investigation.

In summary, the presence of findings that seem to be sometimes conflicting when the susceptibility of visual illusion is measured in groups of people with ASD can be the result of several factors. Different procedures employed, variations in the instructions provided to the participants, differences in control groups and sample sizes, and last but not least, the heterogeneous nature of ASD itself, all seem to be factors that can lead to different results. It is worth noting that, probably because of some aforementioned factors, research in ASD often provides conflicting results. For example, there is no consensus regarding the brain areas involved in the disorder or in its genetic bases (Amaral et al., 2008).

\section{CONCLUSION: NEW PERSPECTIVES ON THE INVOLVEMENT OF VISUAL ILLUSIONS IN THE STUDY OF DEVELOPMENTAL DYSLEXIA AND AUTISM SPECTRUM DISORDER}

The contribution of visual illusions to our understanding of neurodevelopmental disorders seems far from reaching its peak. After reviewing the studies that employed visual illusions to unveil brain mechanisms in DD and ASD, it appears that there have been important steps forward. One aspect that could be improved upon is the method by which visual illusion sensitivity 
is measured. While simply asking if the illusion is perceived or not has the benefit of making the task easier for participants, which are often children or sometimes adult with communications difficulties (i.e., some individuals with ASD), it is probably not the most accurate approach. Constant stimuli or staircases with nulling paradigms (in which different levels of physically countering information are presented to the observer until the illusory effect is nullified) could be the proper approach for obtaining a much more precise measure of visual illusion sensitivity in future research. The challenge will be to develop a paradigm with these methodologies that is still simple enough to be performed by children and individuals with difficulties in communication.

Moreover, we also suggest utilizing visual illusions for other interesting challenges such as:

(i) The early identification of the disorders. DD diagnosis, for example, can be done, by definition, only after reading acquisition. It implies that any potential treatment cannot start before the child reaches 7 or even 8 years old. On the contrary, a deficit in the M-D pathway can be identified much sooner, potentially at infancy. Consequently, developing new visual illusion tasks, capable of testing M-D functionality, can lead to earlier identification of children at risk for DD. Early identification will have a positive cascading effect in the battle against $\mathrm{DD}$ and its negative outcomes. Children identified as at risk for DD could be specifically treated well before the typical age of diagnosis. This preventative approach would improve existing cognitive deficits, and children would potentially reach the age of reading acquisition with a much better toolbox at their disposal for facing the challenge of learning to read. Moreover, brain plasticity is much more evident in the early years of life, and treatment would have a better chance of being effective. Prevention is undeniably the main goal in DD research, and visual illusions could play a leading role in achieving this goal.

Regarding ASD, diagnosis can be done in children as young as 2 years old. However, developing paradigms for infants to show a reduced sensitivity to visual illusions could make the identification of risk for ASD even earlier. Moreover, it will provide other tools to use together with the more traditional measurements in order to make the diagnosis more reliable.

(ii) Longitudinal studies. Another connected area of research where visual illusions could play an important role is in longitudinal studies. These studies are crucial to proving the existence of a causal link between a specific cognitive deficit and the neurodevelopmental disorder. Visual illusions,

\section{REFERENCES}

Agrillo, C., Gori, S., and Beran, M. J. (2015). Do rhesus monkeys (Macaca mulatta) perceive illusory motion? Anim Cogn. 18, 895-910. doi: 10.1007/s10071-0150860-6

Alais, D., and Lorenceau, J. (2002). Perceptual grouping in the Ternus display: evidence for an 'association field' in apparent motion. Vis. Res. 42, 1005-1016. doi: 10.1016/S0042-6989(02)00021-4 measuring the M-D functionality, could be employed at the pre-reading stage. The aim would be discover if future reading disabilities could be explained by a pre-existing deficit in the M-D pathway, and thus eliminate any confound related to noise exclusion mechanisms.

Also for ASD, a longitudinal study showing that less sensitivity to illusions in infancy is causally linked to future ASD symptoms would be of utmost importance, from both theoretical and practical reasons. Such a result result would prove that the weak central coherence is a cause and not a consequence of ASD, and early treatments to strengthen the central coherence in infants at risk for ASD could be developed.

(iii) Efficacy of treatment tests. Finally, visual illusions could be employed to test the efficacy of a treatment for DD or ASD. It is expected that an effective treatment would show a correlation between the reduction of neurodevelopmental disorder symptoms and performance on the visual illusions task.

This role of efficacy tests for treatments could also be extended to prevention programs aiming to reduce the incidence of DD or ASD.

\section{CONCLUSION}

The use of visual illusions as a tool for investigating the brain mechanisms of individuals with neurodevelopmental disorders has already shown to be a very successful approach, and it has the possibility to offer answers in future exciting challenges.

\section{AUTHOR CONTRIBUTIONS}

All authors listed, have made substantial, direct and intellectual contribution to the work, and approved it for publication.

\section{ACKNOWLEDGMENTS}

We thank Pamela Pallett, Julia R. Duggan, and Mago Egitto for their helpful comments on the manuscript. This work was funded with grants by the CARIPARO Foundation ("Borse di Dottorato CARIPARO 2009" and "Progetti di Eccellenza CARIPARO 20122014 rep. no. 1873/2012" to SG and AF) by the University of Padua ("Senior Post Doc Researcher 2014-2016" to SG; Progetto di Ateneo 2011; 2014 to AF). autism. Front. Biosci. 6:D119. doi: 10.2741/allen

Almeida, R. A., Dickinson, J. E., Maybery, M. T., Badcock, J. C., and Badcock, D. R. (2010). A new step towards understanding embedded figures test performance in the autism spectrum: the radial frequency search task. Neuropsychologia 48, 374-381. doi: 10.1016/j.neuropsychologia.2009.09.024

Amaral, D. G., Schumann, C. M., and Nordahl, C. W. (2008). Neuroanatomy of autism. Trends Neurosci. 31, 137-145. doi: 10.1016/j.tins.2007.12.005 
American Psychiatric Association Task Force on DSM-IV (1994). DSM-IV: Diagnostic and Statistical Manual of Mental Disorders, Fifth Edition. Arlington, VI: American Psychiatric Association.

American Psychiatric Association Task Force on DSM-V (2013). DSM-IV: Diagnostic and Statistical Manual of Mental Disorders, Fifth Edition. Arlington, VI: American Psychiatric Association.

Ames, C., and Fletcher-Watson, S. (2010). A review of methods in the study of attention in autism. Dev. Rev. 30, 52-73. doi: 10.1016/j.dr.2009. 12.003

Amitay, S., Ben-Yehudah, G., Banai, K., and Ahissar, M. (2002). Disabled readers suffer from visual and auditory impairments but not from a specific magnocellular deficit. Brain 125, 2272-2285. doi: 10.1093/brain/awf231

Anstis, S., Gori, S., and Wehrhahn, C. (2007). Afterimages and the breathing light illusion. Perception 36, 791-794. doi: 10.1068/p5785

Avery, G. C., and Day, R. H. (1969). Basis of the horizontal-vertical illusion. J. Exp. Psychol. 81:376. doi: 10.1037/h0027737

Baldassi, S., Pei, F., Megna, N., Recupero, G., Viespoli, M., Igliozzi, R., et al. (2009). Search superiority in autism within, but not outside the crowding regime. Vis. Res. 49, 2151-2156. doi: 10.1016/j.visres.2009.06.007

Baron-Cohen, S., Richler, J., Bisarya, D., Gurunathan, N., and Wheelwright, S. (2003). The systemizing quotient: an investigation of adults with Asperger syndrome or high-functioning autism, and normal sex differences. Philos. Trans. R. Soc. Lond. B Biol. Sci. 358, 361-374. doi: 10.1098/rstb.2002.1206

Belmonte, M. K., Allen, G., Beckel-Mitchener, A., Boulanger, L. M., Carper, R. A., and Webb, S. J. (2004). Autism and abnormal development of brain connectivity. J. Neurosci. 24, 9228-9231. doi: 10.1523/JNEUROSCI.334004.2004

Benardete, E. A., Kaplan, E., and Knight, B. W. (1992). Contrast gain control in the primate retina: P cells are not X-like, some M cells are. Vis. Neurosci. 8, 483-486. doi: 10.1017/S0952523800004995

Bertone, A., Mottron, L., Jelenic, P., and Faubert, J. (2005). Enhanced and diminished visuo-spatial information processing in autism depends on stimulus complexity. Brain 128, 2430-2441. doi: 10.1093/brain/awh561

Billino, J., Hamburger, K., and Gegenfurtner, K. R. (2009). Age effects on the perception of motion illusions. Perception 38, 508-521. doi: 10.1068/p5886

Billstedt, E. (2000). Autism and Asperger syndrome: coexistence with other clinical disorders. Acta Psychiatr. Scand. 102, 321-330. doi: 10.1034/j.16000447.2000.102005321.x

Boden, C., and Giaschi, D. (2007). M-stream deficits and reading-related visual processes in developmental dyslexia. Psychol. Bull. 133, 346-366. doi: 10.1037/0033-2909.133.2.346

Bölte, S., Holtmann, M., Poustka, F., Scheurich, A., and Schmidt, L. (2007). Gestalt perception and local-global processing in high-functioning autism. J. Autism Dev. Dis. 37, 1493-1504. doi: 10.1007/s10803-006-0231-x

Bondarko, V. M., and Semenov, L. A. (2004). Size estimates in Ebbinghaus illusion in adults and children of different age. Hum. Physiol. 30, 24-30. doi: 10.1023/B:HUMP.0000013760.85499.17

Bosse, M., Tainturier, M. J., and Valdois, S. (2007). Developmental dyslexia: the visual attention span deficit hypothesis. Cognition 104, 198-230. doi: 10.1016/j.cognition.2006.05.009

Braddick, O. J. (1980). Low-level and high-level processes in apparent motion. Philos. Trans. R. Soc. Lond. B Biol. Sci. 290, 137-151. doi: 10.1098/rstb.1980.0087

Brannan, J. R., and Williams, M. C. (1987). Allocation of visual attention in good and poor readers. Percept. Psychophys. 41, 23-28. doi: 10.3758/BF03208209

Bregman, A. S., and Achim, A. (1973). Visual stream Segregation. Percept. Psychophys. 13, 451-454. doi: 10.3758/BF03205801

Brosvic, G. M., Dihoff, R. E., and Fama, J. (2002). Age-related susceptibility to the Muller-Lyer and the horizontal-vertical illusions. Percept. Mot. Skills 94, 229-234. doi: 10.2466/pms.2002.94.1.229

Brown, C., Gruber, T., Boucher, J., Rippon, G., and Brock, J. (2005). Gamma abnormalities during perception of illusory figures in autism. Cortex 41, 364-376. doi: 10.1016/S0010-9452(08)70273-9

Buchholz, J., and Aimola Davies, A. (2007). Attentional blink deficits observed in dyslexia depend on task demands. Vis. Res. 47, 1292-1302. doi: 10.1016/j.visres.2006.11.028

Buchholz, J., and McKone, E. (2004). Adults with dyslexia show deficits on spatial frequency doubling and visual attention tasks. Dyslexia 10, 24-43. doi: $10.1002 /$ dys. 263
Bulf, H., Valenza, E., and Simion, F. (2009). The visual search of an illusory figure: a comparison between 6-month-old infants and adults. Perception 38, 1313-1327. doi: $10.1068 /$ p6272

Burr, D. (2000). Motion vision: are 'speed lines' used in human visual motion? Curr. Biol. 10, R440-R443. doi: 10.1016/S0960-9822(00)00545-5

Caron, M. J., Mottron, L., Berthiaume, C., and Dawson, M. (2006). Cognitive mechanisms, specificity and neural underpinnings of visuospatial peaks in autism. Brain 129, 1789-1802. doi: 10.1093/brain/awl072

Cestnick, L., and Coltheart, M. (1999). The relationship between languageprocessing and visual-processing deficits in developmental dyslexia. Cognition 71, 231-255. doi: 10.1016/S0010-0277(99)00023-2

Chen, Y., Norton, D. J., McBain, R., Gold, J., Frazier, J. A., and Coyle, J. T. (2012). Enhanced local processing of dynamic visual information in autism: evidence from speed discrimination. Neuropsychologia 50, 733-739. doi: 10.1016/j.neuropsychologia.2012.01.007

Chouinard, P. A., Noulty, W. A., Sperandio, I., and Landry, O. (2013). Global processing during the Müller-Lyer illusion is distinctively affected by the degree of autistic traits in the typical population. Exp. Brain Res. 230, 219-231. doi: 10.1007/s00221-013-3646-6

Conway, B. R., Kitaoka, A., Yazdanbakhsh, A., Pack, C. C., and Livingstone, M. S. (2005). Neural basis for a powerful static motion illusion. J. Neurosci. 25, 5651-5656. doi: 10.1523/JNEUROSCI.1084-05.2005

Corbetta, M., and Shulman, G. L. (2002). Control of goal-directed and stimulus-driven attention in the brain. Nat. Rev. Neurosci. 3, 201-215. doi: $10.1038 /$ nrn755

Corbetta, M., and Shulman, G. L. (2011). Spatial neglect and attention networks. Annu. Rev. Neurosci. 34, 569-599. doi: 10.1146/annurev-neuro-061010113731

Coren, S., and Girgus, J. S. (1978). Seeing is Deceiving: The Psychology of Visual Illusions. Lawrence: Erlbaum.

Dakin, S., and Frith, U. (2005). Vagaries of visual perception in autism. Neuron 48, 497-507. doi: 10.1016/j.neuron.2005.10.018

Daneyko, O., Zavagno, D., and Zanuttini, L. (2011). Lightness effects in Delboeuf and Ebbinghaus size-contrast illusions. Perception 40:464. doi: 10.1068/ p6622

Davis, C., Castles, A., McAnally, K., and Gray, J. (2001). Lapses of concentration and dyslexic performance on the Ternus task. Cognition 81, B21-B31. doi: 10.1016/S0010-0277(01)00129-9

Dawson, M. R. (1991). The how and why of what went where in apparent motion: modeling solutions to the motion correspondence problem. Psychol. Rev. 98, 569-603. doi: 10.1037/0033-295X.98.4.569

de Brouwer, A. J., Brenner, E., Medendorp, W. P., and Smeets, J. B. (2014). Time course of the effect of the Müller-Lyer illusion on saccades and perceptual judgments. J. Vis. 14:4. doi: 10.1167/14.1.4

Dosenbach, N. U., Fair, D. A., Cohen, A. L., Schlaggar, B. L., and Petersen, S. E. (2008). A dual-networks architecture of top-down control. Trends Cogn. Sci. 12, 99-105. doi: 10.1016/j.tics.2008.01.001

Eagleman, D. M. (2001). Visual illusions and neurobiology. Nat. Rev. Neurosci. 2001, 920-926. doi: 10.1038/35104092

Ebbinghaus, H. (1902). Grundzüge der Psychologie, Vol. 1. Leipzig: Verlag von Veit \& Comp.

Elsabbagh, M., Fernandes, J., Jane Webb, S., Dawson, G., Charman, T., Johnson, M. H., et al. (2013). Disengagement of visual attention in infancy is associated with emerging autism in toddlerhood. Biol. Psychiatry 74, 189-194. doi: 10.1016/j.biopsych.2012.11.030

Elsabbagh, M., and Johnson, M. H. (2010). Getting answers from babies about autism. Trends Cogn. Sci. 14, 81-87. doi: 10.1016/j.tics.2009.12.005

Eriksen, C. W., and St. James, J. D. (1986). Visual attention within and around the field of focal attention: a zoom lens model. Percept. Psychophys. 40, 225-240. doi: 10.3758/BF03211502

Facoetti, A. (2001). Facilitation and inhibition mechanisms of human visuospatial attention in a non-search task. Neurosci. Lett. 298, 45-48. doi: 10.1016/S03043940(00)01719-5

Facoetti, A. (2012). "Spatial attention disorders in developmental dyslexia: Towards the prevention of reading acquisition deficits," in Visual Aspect of Dyslexia, eds J. Stein and Z. Kapoula (Oxford: Oxford University Press), 123-136.

Facoetti, A., Corradi, N., Ruffino, M., Gori, S., and Zorzi, M. (2010a). Visual spatial attention and speech segmentation are both impaired in preschoolers 
at familial risk for developmental dyslexia. Dyslexia 16, 226-239. doi: 10.1002/ dys. 413

Facoetti, A., Lorusso, M. L., Cattaneo, C., Galli, R., and Molteni, M. (2005). Visual and auditory attentional capture are both sluggish in children with developmental dyslexia. Acta Neurobiol. Exp. 65, 61-72.

Facoetti, A., and Molteni, M. (2000). Is attentional focusing an inhibitory process at distractor location? Brain Res. Cogn. Brain Res. 1-2, 185-188. doi: 10.1016/S0926-6410(00)00031-8

Facoetti, A., and Molteni, M. (2001). The gradient of visual attention in developmental dyslexia. Neuropsychologia 39, 352-357. doi: 10.1016/S00283932(00)00138-X

Facoetti, A., Paganoni, P., Turatto, M., Marzola, V., and Mascetti, G. G. (2000). Visual-spatial attention in developmental dyslexia. Cortex 36, 109-123. doi: 10.1016/S0010-9452(08)70840-2

Facoetti, A., Ruffino, M., Peru, A., Paganoni, P., and Chelazzi, L. (2008). Sluggish engagement and disengagement of non-spatial attention in dyslexic children. Cortex 44, 1221-1233. doi: 10.1016/j.cortex.2007.10.007

Facoetti, A., Trussardi, A. N., Ruffino, M., Lorusso, M. L., Cattaneo, C., Galli, R., et al. (2010b). Multisensory spatial attention deficits are predictive of phonological decoding skills in developmental dyslexia. J. Cogn. Neurosci. 22, 1011-1025. doi: 10.1162/jocn.2009.21232

Facoetti, A., Turatto, M., Lorusso, M. L., and Mascetti, G. G. (2001). Orienting of visual attention in dyslexia: evidence for asymmetric hemispheric control of attention. Exp. Brain Res. 138, 46-53. doi: 10.1007/s002210100700

Facoetti, A., Zorzi, M., Cestnick, L., Lorusso, M. L., Molteni, M., Paganoni, P., et al. (2006). The relationship between visuo-spatial attention and nonword reading in developmental dyslexia. Cogn. Neuropsychol. 23, 841-855. doi: 10.1080/02643290500483090

Fantoni, C., and Pinna, B. (2008). Apparent motion by edge discontinuities. Perception 37, 973-992. doi: 10.1068/p5782

Farmer, M. E., and Klein, R. M. (1995). The evidence for a temporal processing deficit linked to dyslexia: a review. Psychon. Bull. Rev. 2, 460-493. doi: 10.3758/BF03210983

Fick, A. (1851). De Errore Quodam Optico Asymmetrica Bulbi Effecto. Marburg: J. A. Kochin.

Fisher, G. H. (1968). Gradients of distortion seen in the context of the Ponzo illusion and other contours. Q. J. Exp. Psychol. 20, 212-217. doi: 10.1080/14640746808400153

Franceschini, S., Bertoni, S., Ronconi, L., Molteni, M., Gori, S., and Facoetti, A. (2015). "Shall we play a game? Improving reading through action video games in developmental dyslexia. Curr. Dev. Disord. Rep. 2, 318-329. doi: 10.1007/s40474-015-0064-4

Franceschini, S., Gori, S., Ruffino, M., Pedrolli, K., and Facoetti, A. (2012). A causal link between visual spatial attention and reading acquisition. Curr. Biol. 22, 814-819. doi: 10.1016/j.cub.2012.03.013

Franceschini, S., Gori, S., Ruffino, M., Viola, S., Molteni, M., and Facoetti, A. (2013). Action video games make dyslexic children read better. Curr. Biol. 23, 462-466. doi: 10.1016/j.cub.2013.01.044

Frith, U., and Happé, F. (1994). Autism: beyond theory of mind. Cognition 50, 115-132. doi: 10.1016/0010-0277(94)90024-8

Galmonte, A., Soranzo, A., Rudd, M. E., and Agostini, T. (2015). The phantom illusion. Vision Res. 117, 49-58. doi: 10.1016/j.visres.2015.10.007

Geiger, G., Cattaneo, C., Galli, R., Pozzoli, U., Lorusso, M. L., Facoetti, A., et al. (2008). Wide and diffuse perceptual modes characterize dyslexics in vision and audition. Perception 37, 1745-1764. doi: 10.1068/p6036

Giora, E., and Gori, S. (2010). The perceptual expansion of a filled area depends on textural characteristics. Vision Res. 50, 2466-2475. doi: 10.1016/j.visres.2010.08.033

Giraldo-Chica, M., Hegarty, J. P. I. I., and Schneider, K. A. (2015). Morphological differences in the lateral geniculate nucleus associated with dyslexia. Neuroimage Clin. 20, 830-836. doi: 10.1016/j.nicl.2015.03.011

Gliga, T., Bedford, R., Charman, T., Johnson, M. H., and Basis Team. (2015). Enhanced visual search in infancy predicts emerging autism symptoms. Curr. Biol. 25, 1727-1730. doi: 10.1016/j.cub.2015.05.011

Goodale, M. A., and Milner, A. D. (1992). Separate visual pathways for perception and action. Trends Neurosci. 15, 20-25. doi: 10.1016/0166-2236(92)90344-8

Gori, S., Agrillo, C., Dadda, M., and Bisazza, A. (2014). Do fish perceive illusory motion? Sci. Rep. 4:6443. doi: 10.1038/srep06443
Gori, S., and Facoetti, A. (2014). Perceptual learning as a possible new approach for remediation and prevention of developmental dyslexia. Vision Res. 99, 78-87. doi: 10.1016/j.visres.2013.11.011

Gori, S., and Facoetti, A. (2015). How the visual aspects can be crucial in reading acquisition: the intriguing case of crowding and developmental dyslexia. J. Vis. 2015, 15.1.8. doi: 10.1167/15.1.8

Gori, S., Giora, E., and Agostini, T. (2010a). Measuring the Breathing Light Illusion by means of induced simultaneous contrast. Perception 39, 5-12. doi: $10.1068 / \mathrm{p} 6489$

Gori, S., Giora, E., and Stubbs, D. A. (2010b). Perceptual compromise between apparent and veridical motion indices: the Unchained-Dots illusion. Perception 39, 863-866. doi: 10.1068/p6678

Gori, S., Giora, E., and Pedersini, R. (2008a). Perceptual multistability in figureground segregation using motion stimuli. Acta Psychol. 129, 399-409. doi: 10.1016/j.actpsy.2008.09.004

Gori, S., Giora, E., Yazdanbakhsh, A., and Mingolla, E. (2011). A new motion illusion based on competition between two kinds of motion processing units: the accordion grating. Neural Netw. 24, 1082-1092. doi: 10.1016/j.neunet.2011.06.017

Gori, S., Giora, E., Yazdanbakhsh, A., and Mingolla, E. (2013). The novelty of the accordion-grating. Neural Netw. 39:52. doi: 10.1016/j.neunet.2012. 07.008

Gori, S., and Hamburger, K. (2006). A new motion illusion: the rotating-TiltedLines illusion. Perception 35, 853-857. doi: 10.1068/p5531

Gori, S., Hamburger, K., and Spillmann, L. (2006). Reversal of apparent rotation in the Enigma-figure with and without motion adaptation and the effect of T-junctions. Vision Res. 46, 3267-3273. doi: 10.1016/j.visres.2006. 03.009

Gori, S., Mascheretti, S., Giora, E., Ronconi, L., Ruffino, M., Quadrelli, E., et al. (2015a). The DCDC2 intron 2 deletion impairs illusory motion perception unveiling the selective role of magnocellular-dorsal stream in reading (dis)ability. Cereb. Cortex 25, 1685-1695. doi: 10.1093/cercor/ bhu234

Gori, S., Pedersini, R., and Giora, E. (2008b). How do painters represent motion in garments? Graphic invariants across centuries. Spat. Vis. 21, 201-227. doi: $10.1163 / 156856808784532635$

Gori, S., Seitz, A. R., Ronconi, L., Franceschini, S., and Facoetti, A. (2015b). Multiple causal links between magnocellular-dorsal pathway deficit and developmental dyslexia. Cereb. Cortex doi: 10.1093/cercor/bhv206 [Epub ahead of print].

Gori, S., and Spillmann, L. (2010). Detection vs. grouping thresholds for elements differing in spacing, size and luminance. An alternative approach towards the psychophysics of Gestalten. Vision Res. 50, 1194-1202. doi: 10.1016/j.visres.2010.03.022

Gori, S., and Stubbs, D. A. (2006). A new set of illusions-the dynamic luminancegradient illusion and the breathing light illusion. Perception 35, 1573-1577. doi: $10.1068 / \mathrm{p} 5668$

Gori, S., and Stubbs, D. A. (2014). "Motion illusions as a psychophysical tool to investigate the visual system," in Perception Beyond Gestalt: Progress in Vision Research, eds A. Geremek, M. W. Greenlee, and S. Magnussen (New York, NY: Psychology Press), 128-143.

Gori, S., and Yazdanbakhsh, A. (2008). The riddle of the Rotating-Tilted-Lines illusion. Perception 37, 631-635. doi: 10.1068/p5770

Goswami, U. (2003). Why theories about developmental dyslexia require developmental designs. Trends Cogn. Sci. 7, 534-540. doi: 10.1016/j.tics.2003.10.003

Green, R. T., and Hoyle, E. M. (1963). The Poggendorff illusion as a constancy phenomenon. Nature 200, 611-612. doi: 10.1038/200611a0

Greenaway, R., and Plaisted, K. (2005). Top-down attentional modulation in autistic spectrum disorders is stimulus-specific. Psychol. Sci. 16, 987-994. doi: 10.1111/j.1467-9280.2005.01648.x

Gregory, R. L. (1968). Visual illusions. Sci. Am. 219, 66-76. doi: 10.1038/scientificamerican1168-66

Gregory, R. L. (1997). Visual illusions classified. Trends Cogn. Sci. 1, 190-194. doi: 10.1016/S1364-6613(97)01060-7

Grubb, M. A., Behrmann, M., Egan, R., Minshew, N. J., Carrasco, M., and Heeger, D. J. (2013a). Endogenous spatial attention: evidence for intact functioning in adults with autism. Autism Res. 6, 108-118. doi: 10.1002/aur.1269 
Grubb, M. A., Behrmann, M., Egan, R., Minshew, N. J., Heeger, D. J., and Carrasco, M. (2013b). Exogenous spatial attention: evidence for intact functioning in adults with autism spectrum disorder. J. Vis. 13:9. doi: $10.1167 / 13.14 .9$

Hamburger, K. (2012). Still motion? Motion illusions and luminance contrast. Perception 41, 113-116. doi: 10.1068/p7005

Hamburger, K. (2016). Visual illusions based on processes: new classification system needed. Perception doi: 10.1177/0301006616629038 [Epub ahead of print].

Hamburger, K., Hansen, T., and Gegenfurtner, K. R. (2007). Geometric-optical illusions at isoluminance. Vision Res. 47, 3276-3285. doi: 10.1016/j.visres. 2007.09.004

Hamm, L. M., Black, J., Dai, S., and Thompson, B. (2014). Global processing in amblyopia: a review. Front. Psychol. 17:583. doi: 10.3389/fpsyg.2014.00583

Happé, F. (1996). Studying weak central coherence at low levels: children with autism do not succumb to visual illusions. A research note. J. Child Psychol. Psychiatry. 37, 873-877. doi: 10.1111/j.1469-7610.1996.tb01483.x

Happé, F. (1999). Autism: cognitive deficit or cognitive style. Trends Cogn. Sci. 3, 216-222. doi: 10.1016/S1364-6613(99)01318-2

Happé, F., and Frith, U. (2006). The weak coherence account: detail-focused cognitive style in autism spectrum disorders. J. Autism Dev. Disord. 36, 5-25. doi: 10.1007/s10803-005-0039-0

Hari, R., and Kiesila, P. (1996). Deficit of temporal auditory processing in dyslexic adults. Neurosci. Lett. 205, 138-140. doi: 10.1016/0304-3940(96)12393-4

Hari, R., and Renvall, H. (2001). Impaired processing of rapid stimulus sequences in dyslexia. Trends Cogn. Sci. 5, 525-532. doi: 10.1016/S1364-6613(00)01801-5

Hari, R., Renvall, H., and Tanskanen, T. (2001). Left minineglect in dyslexic adults. Brain 124, 1373-1380. doi: 10.1093/brain/124.7.1373

Hari, R., Valta, M., and Uutela, K. (1999). Prolonged attentional dwell time in dyslexic adults. Neurosci. Lett. 271, 202-204. doi: 10.1016/S03043940(99)00547-9

Harrar, V., Tammam, J., Pérez-Bellido, A., Pitt, A., Stein, J., and Spence, C. (2014) Multisensory integration and attention in developmental dyslexia. Curr. Biol. 24, 531-535. doi: 10.1016/j.cub.2014.01.029

Heitger, F., von der Heydt, R., Peterhans, E., Rosenthaler, L., and Kübler, O. (1998). Simulation of neural contour mechanisms: representing anomalous contours. Image Vis. Comput. 16, 407-421. doi: 10.1016/S0262-8856(97) 00083-8

Helenius, P., Uutela, K., and Hari, R. (1999). Auditory stream segregation in dyslexic adults. Brain 122, 907-913. doi: 10.1093/brain/122.5.907

Hering, E. (1861). Beiträge zur Physiologie. I. Zur Lehre vom Ortssinne der Netzhaut. Leipzig: Engelmann.

Hikosaka, O., Miyauchi, S., and Shimojo, S. (1993). Visual attention revealed by an illusion of motion. Neurosci. Res. 18, 11-18. doi: 10.1016/0168-0102(93)90100-5

Hirsch, J., DeLaPaz, R. L., Relkin, N. R., Victor, J., Kim, K., Li, T., et al. (1995). Illusory contours activate specific regions in human visual cortex: evidence from functional magnetic resonance imaging. Proc. Natl. Acad. Sci. U.S.A. 92, 6469-6473. doi: 10.1073/pnas.92.14.6469

Holt-Hansen, K. (1973). Experienced lengthening and shortening of a straight line fixated in the middle and briefly exposed. Percept. Motor Skills 36, 1023-1029. doi: 10.2466/pms.1973.36.3c.1023

Hoy, J. A., Hatton, C., and Hare, D. (2004). Weak central coherence: a cross-domain phenomenon specific to autism? Autism 8, 267-281. doi: $10.1177 / 1362361304045218$

ICD 10 (1992). wDisability [Internet]. Atlanta, GA: National Center for Health Statistics. Available at: http://www.cdc.gov/nchs/icd.htm

Iles, J., Walsh, V., and Richardson, A. (2000). Visual search performance in dyslexia. Dyslexia 6, 163-177. doi: 10.1002/1099-0909(200007/09)6

Ito, H. (2012). Illusory object motion in the centre of a radial pattern: the Pursuit-Pursuing illusion. Iperception 3, 59-87. doi: 10.1068/i0430

Johannes, S., Kussmaul, C. L., Münte, T. F., and Mangun, G. R. (1996). Developmental dyslexia: passive visual stimulation provides no evidence for a magnocellular processing defect. Neuropsychologia 34, 1123-1127. doi: 10.1016/0028-3932(96)00026-7

Johnson, M. H. (2011). Interactive specialization: a domain-general framework for human functional brain development? Dev. Cogn. Neurosci. 1, 7-21. doi: 10.1016/j.dcn.2010.07.003
Jolliffe, T., and Baron-Cohen, S. (1997). Are people with autism and asperger syndrome faster than normal on the embedded figures test. J. Child Psychol. Psychiatry 38, 527-534. doi: 10.1111/j.1469-7610.1997.tb01539.x

Jones, M. W., Branigan, H. P., and Kelly, M. L. (2008). Visual deficits in developmental dyslexia: relationships between non-linguistic visual tasks and their contribution to components of reading. Dyslexia 14, 95-115. doi: 10.1002/dys.345

Kanizsa, G. (1955). Margini quasi-percettivi in campi con stimolazione omogenea. Rivista Psicol. 49, 7-30.

Kaplan, E., and Shapley, R. (1982). X and Y cells in the lateral geniculate nucleus of macaque monkeys. J. Physiol. (Lond.) 330, 125-143. doi: 10.1113/jphysiol.1982.sp014333

Karmiloff-Smith, A. (1998). Development itself is the key to understanding developmental disorders. Trends Cogn. Sci. 2, 389-398. doi: 10.1016/S13646613(98)01230-3

Kelly, D. (1966). Frequency doubling in visual responses. JOSA 56, 1628-1632. doi: 10.1364/JOSA.56.001628

Kelly, D. (1981). Nonlinear visual responses to flickering sinusoidal gratings. JOSA 71, 1051-1055. doi: 10.1364/JOSA.71.001051

Kevan, A., and Pammer, K. (2008). Visual deficits in pre-readers at familial risk for dyslexia. Vis. Res. 48, 2835-2839. doi: 10.1016/j.visres.2008.09.022

Kevan, A., and Pammer, K. (2009). Predicting early reading skills from pre-reading measures of dorsal stream functioning. Neuropsychologia 47, 3174-3181. doi: 10.1016/j.neuropsychologia.2009.07.016

Kitaoka, A., and Ashida, H. (2007). A variant of the anomalous motion illusion based upon contrast and visual latency. Perception 36, 1019-1035. doi: $10.1068 / \mathrm{p} 5362$

Koyama, M. S., Di Martino, A., Kelly, C., Jutagir, D. R., Sunshine, J., Schwartz, S. J., et al. (2013). Cortical signatures of dyslexia and remediation: an intrinsic functional connectivity approach. PLOS ONE 8:e55454. doi: 10.1371/journal.pone.0055454

Künnapas, T. M. (1955). An analysis of the "vertical-horizontal illusion." J. Exp. Psychol. 49, 134-140.

Lallier, M., Tainturier, M. J., Dering, B., Donnadieu, S., Valdois, S., and Thierry, G. (2010). Behavioral and ERP evidence for amodal sluggish attentional shifting in developmental dyslexia. Neuropsychologia 48, 4125-4135. doi: 10.1016/j.neuropsychologia.2010.09.027

Lallier, M., Thierry, G., Tainturier, M. J., Donnadieu, S., Peyrin, C., Billard, C., et al. (2009). Auditory and visual stream segregation in children and adults: an assessment of the amodality assumption of the 'sluggish attentional shifting' theory of dyslexia. Brain Res. 1302, 132-147. doi: 10.1016/j.brainres.2009. 07.037

Liu, D., Chen, X., and Chung, K. K.-H. (2015). Performance in a visual search task uniquely predicts reading abilities in third-grade Hong Kong Chinese children. Sci. Stud. Read. 4, 307-324. doi: 10.1080/10888438.2015.1030749

Livingstone, M. S., and Hubel, D. H. (1987). Psychophysical evidence for separate channels for the perception of form, color, movement, and depth. J. Neurosci. 7 , 3416-3468.

Livingstone, M. S., Rosen, G. D., Drislane, F. W., and Galaburda, A. M. (1991). Physiological and anatomical evidence for a magnocellular defect in developmental dyslexia. Proc. Natl. Acad. Sci. U.S.A. 88, 7943-7947. doi: 10.1073/pnas.88.18.7943

Lobier, M. A., Peyrin, C., Pichat, C., Le Bas, J. F., and Valdois, S. (2014). Visual processing of multiple elements in the dyslexic brain: evidence for a superior parietal dysfunction. Front. Hum. Neurosci. 7:479. doi: 10.3389/fnhum.2014.00479

Lovaas, O. I., and Schreibman, L. (1971). Stimulus overselectivity of autistic children in a two stimulus situation. Behav. Res. Ther. 9, 305-310. doi: 10.1016/0005-7967(71)90042-8

Macknik, S. L., and Livingstone, M. S. (1998). Neuronal correlates of visibility and invisibility in the primate visual system. Nat. Neurosci. 1, 144-149. doi: $10.1038 / 393$

Maddess, T., Hemmi, J. M., and James, A. C. (1992). Evidence for spatial aliasing effects in the Y-like cells of the magnocellular visual pathway. Vision Res. 38, 1843-1859. doi: 10.1016/S0042-6989(97)00344-1

Maloney, L. T., Dal Martello, M. F., Sahm, C., and Spillmann, L. (2005). Past trials influence perception of ambiguous motion quartets through 
pattern completion. Proc. Natl. Acad. Sci. U.S.A. 102, 3164-3169. doi: 10.1073/pnas.0407157102

Mamassian, P., and de Montalembert, M. (2010). A simple model of the verticalhorizontal illusion. Vision Res. 50, 956-962. doi: 10.1016/j.visres.2010.03.005

Manjaly, Z. M., Bruning, N., Neufang, S., Stephan, K. E., Brieber, S., Marshall, J. C., et al. (2007). Neurophysiological correlates of relatively enhanced local visual search in autistic adolescents. Neuroimage 35, 283-291. doi: 10.1016/j.neuroimage.2006.11.036

Mann, T. A., and Walker, P. (2003). Autism and a deficit in broadening the spread of visual attention. J. Child Psychol. Psychiatry 44, 274-284. doi: 10.1111/14697610.00120

Manning, C., Tibber, M. S., Charman, T., Dakin, S. C., and Pellicano, E. (2015). Enhanced integration of motion information in children with autism. J. Neurosci. 35, 6979-6986.

Marino, C., Scifo, P., Della Rosa, P. A., Mascheretti, S., Facoetti, A., Lorusso, M. L., et al. (2014). The DCDC2/intron 2 deletion and white matter disorganization: focus on developmental dyslexia. Cortex 57, 227-243. doi: 10.1016/j.cortex.2014.04.016

Marrocco, R. T., McClurkin, J. W., and Young, R. A. (1982). Spatial summation and conduction latency classification of cells of the lateral geniculate nucleus of macaques. J. Neurosci. 2, 1275-1291.

Mascheretti, S., Bureau, A., Battaglia, M., Simone, D., Quadrelli, E., Croteau, J., et al. (2013). An assessment of gene-by-environment interactions in developmental dyslexia-related phenotypes. Genes Brain Behav. 12, 47-55. doi: $10.1111 / \mathrm{gbb} .12000$

Maunsell, J. H. R., and Newsome, W. T. (1987). Visual processing in monkey extrastriate cortex. Annu. Rev. Neurosci. 10, 363-401. doi: 10.1146/annurev.ne.10.030187.002051

Mazer, J. A. (2011). Spatial attention, feature-based attention, and saccades: three sides of one coin. Biol. Psychiatry 69, 1147-1152. doi: 10.1016/j.biopsych.2011.03.014

McCarthy, J. D., Kupitz, C., and Caplovitz, G. P. (2013). The binding ring illusion: Assimilation affects the perceived size of a circular array. Cereb. Cortex 2:58. doi: 10.12688/f1000research.2-58.v2

Meng, H., Smith, S. D., Hager, K., Held, M., Liu, J., Olson, R. K., et al. (2005). DCDC2 is associated with reading disability and modulates neuronal development in the brain. Proc. Natl. Acad. Sci. U.S.A. 102, 17053-17058. doi: 10.1073/pnas.0508591102

Merigan, W. H., and Maunsell, J. H. (1993). How parallel are the primate visual pathways? Annu. Rev. Neurosci. 16, 369-402. doi: 10.1146/annurev.ne.16.030193.002101

Mestry, N., Menneer, T., Wenger, M. J., Benikos, N., McCarthy, R. A., and Donnelly, N. (2014). The role of configurality in the Thatcher illusion: an ERP study. Psychon. Bull. Rev. 22, 445-452. doi: 10.3758/s13423-014-0705-3

Mikami, A. (1991). Direction selective neurons respond to short-range and longrange apparent motion stimuli in macaque visual area MT. Int. J. Neurosci. 61, 101-112. doi: 10.3109/00207459108986278

Mikellidou, K., and Thompson, P. (2013). The vertical-horizontal illusion: assessing the contributions of anisotropy, abutting, and crossing to the misperception of simple line stimuli. J. Vis. 13:7. doi: 10.1167/13.8.7

Milne, E., and Scope, A. (2008). Are children with autistic spectrum disorders susceptible to contour illusions? Br. J. Dev. Psychol. 26, 91-102. doi: 10.1348/026151007X202509

Milne, E., Swettenham, J., Hansen, P., Campbell, R., Jeffries, H., and Plaisted, K. (2002). High motion coherence thresholds in children with autism. J. Child Psychol. Psychiatry 2002, 255-263. doi: 10.1111/1469-7610. 00018

Mishkin, M., and Ungerleider, L. G. (1982). Contribution of striate inputs to the visuospatial functions of parieto-preoccipital cortex in monkeys. Behav. Brain Res. 6, 57-77. doi: 10.1016/0166-4328(82)90081-X

Mitchell, P., Mottron, L., Soulières, I., and Ropar, D. (2010). Susceptibility to the Shepard illusion in participants with autism: reduced top-down influences within perception? Autism Res. 3, 113-119. doi: 10.1002/aur.130

Mottron, L., Burack, J. A., Iarocci, G., Belleville, S., and Enns, J. T. (2003). Locally oriented perception with intact global processing among adolescents with high-functioning autism: evidence from multiple paradigms. J. Child Psychol. Psychiatry 44, 904-913. doi: 10.1111/1469-7610.00174
Mottron, L., Dawson, M., Soulières, I., Hubert, B., and Burack, J. (2006). Enhanced perceptual functioning in autism: an update, and eight principles of autistic perception. J. Autism. Dev. Disord. 36, 27-43. doi: 10.1007/s10803-0050040-7

Muckli, L., Kohler, A., Kriegeskorte, N., and Singer, W. (2005). Primary visual cortex activity along the apparent-motion trace reflects illusory perception. PLoS Biol. 3:e265. doi: 10.1371/journal.pbio.0030265

Müller-Lyer, F. C. (1889). Optische urteilstäuschungen. Arch. Anat. Physiol. Physiol. Abteilung 2(Suppl.), 263-270.

Mundy, P. (2003). Annotation: the neural basis of social impairments in autismThe role of the dorsal medial-frontal cortex and anterior cingulate system. J. Child Psychol. Psychiatry 44, 793-809. doi: 10.1111/1469-7610.00165

NINDS (2001/2015). Dyslexia information page. Natl. Instit. Neurol. Disord. Stroke Natl. Instit. Health 29:2015.

Ninio, J. (2014). Geometrical illusions are not always where you think they are: a review of some classical and less classical illusions, and ways to describe them. Front. Hum. Neurosci. 8:856. doi: 10.3389/fnhum.2014.00856

Notredame, C. E., Pins, D., Deneve, S., and Jardri, R. (2014). What visual illusions teach us about schizophrenia. Front. Integr. Neurosci. 12:63. doi: 10.3389/fnint.2014.00063

Olulade, O. A., Napoliello, E. M., and Eden, G. F. (2013). Abnormal visual motion processing is not a cause of dyslexia. Neuron 79, 1-11. doi: 10.1016/j.neuron.2013.05.002

O’Riordan, M. A., Plaisted, K. C., Driver, J., and Baron-Cohen, S. (2001). Superior visual search in autism. J. Exp. Psychol. Hum. Percept. Perform. 27, 719-730.

Otero-Millan, J., Macknik, S. L., and Martinez-Conde, S. (2012). Microsaccades and blinks trigger illusory rotation in the "rotating snakes" illusion. J. Neurosci. 32, 6043-6051. doi: 10.1523/JNEUROSCI.5823-11.2012

Pammer, K. (2014). Temporal sampling in vision and the implications for dyslexia. Front. Hum. Neurosci. 7:933. doi: 10.3389/fnhum.2013.00933

Pammer, K., Lavis, R., and Cornelissen, P. (2004). Visual encoding mechanisms and their relationship to text presentation preference. Dyslexia 10, 77-94. doi: $10.1002 /$ dys. 264

Pammer, K., and Lovegrove, W. (2001). The influence of color on transient system activity: implications for dyslexia research. Percept. Psychophys. 63, 490-500. doi: 10.3758/BF03194415

Pammer, K., and Wheatley, C. (2001). Isolating the M (y)-cell response in dyslexia using the spatial frequency doubling illusion. Vision Res. 41, 2139-2147. doi: 10.1016/S0042-6989(01)00092-X

Parks, T. E. (2013). On depth processing in the production of the Ponzo illusion: two problems and a solution. Perception 42, 242-244. doi: 10.1068/p7422

Pascual-Leone, A., and Walsh, V. (2001). Fast back projections from the motion to the primary visual area necessary for visual awareness. Science 292, 510-512. doi: 10.1126/science.1057099

Pei, F., Baldassi, S., and Norcia, A. M. (2014). Electrophysiological measures of low-level vision reveal spatial processing deficits and hemispheric asymmetry in autism spectrum disorder. J. Vis. 14:3. doi: 10.1167/14.11.3

Pei, F., Baldassi, S., Procida, G., Igliozzi, R., Tancredi, R., Muratori, F., et al. (2009). Neural correlates of texture and contour integration in children with autism spectrum disorders. Vision Res. 49, 2140-2150. doi: 10.1016/j.visres.2009.06.006

Peterhans, E., and der Heydt, R. (1989). Mechanisms of contour perception in monkey visual cortex. II. Contours bridging gaps. J. Neurosci. 9, 1749-1763.

Pinna, B., Brelstaff, G., and Spillmann, L. (2001). Surface color from boundaries: a new 'watercolor' illusion. Vision Res. 41, 2669-2676. doi: 10.1016/S00426989(01)00105-5

Pinna, B., Spillmann, L., and Werner, J. S. (2003). Anomalous induction of brightness and surface qualities: a new illusion due to radial lines and chromatic rings. Perception 32, 1289-1305. doi: 10.1068/p3475

Plewan, T., Weidner, R., Eickhoff, S. B., and Fink, G. R. (2012). Ventral and dorsal stream interactions during the perception of the Müller-Lyer illusion: evidence derived from fMRI and dynamic causal modeling. J. Cogn. Neurosci. 24, 2015-2029. doi: 10.1162/jocn_a_00258

Ponzo, M. (1911). Intorno ad alcune illusioni nel campo delle sensazioni tattili sull'illusione di Aristotele e fenomeni analoghi. Arch. Gesamte Psychol. 16, 307-345.

Psalta, L., Young, A. W., Thompson, P., and Andrews, T. J. (2014). The Thatcher illusion reveals orientation dependence in brain regions involved in processing 
facial expressions. Psychol. Sci. 25, 128-136. doi: 10.1177/09567976135 01521

Riva, V., Marino, C., Giorda, R., Molteni, M., and Nobile, M. (2014). The role of DCDC2 genetic variants and low socioeconomic status in vulnerability to attention problems. Eur. Child Adolesc. Psychiatry 24, 309-318. doi: 10.1007/s00787-014-0580-5

Roach, N. W., and Hogben, J. H. (2007). Impaired filtering of behaviourally irrelevant visual information in dyslexia. Brain 130, 771-785. doi: 10.1093/brain/awl353

Robertson, C. E., Kravitz, D. J., Freyberg, J., Baron-Cohen, S., and Baker, C. I. (2013). Tunnel vision: sharper gradient of spatial attention in autism. J. Neurosci. 33, 6776-6781. doi: 10.1523/JNEUROSCI.5120-12.2013

Rogers, B. (2014). Delusions about illusions. Perception 43, 840-845.

Ronconi, L., Basso, D., Gori, S., and Facoetti, A. (2014a). TMS on right frontal eye fields induces an inflexible focus of attention. Cereb. Cortex 24, 396-402. doi: 10.1093/cercor/bhs319

Ronconi, L., Facoetti, A., Bulf, H., Franchin, L., Bettoni, R., and Valenza, E. (2014b). Paternal autistic traits are predictive of infants visual attention. J. Autism Dev. Disord. 44, 1556-1564. doi: 10.1007/s10803-013-2018-1

Ronconi, L., Franchin, L., Valenza, E., Gori, S., and Facoetti, A. (2016). The attentional 'zoom-lens' in 8-month-old infants. Dev. Sci. 19, 145-154. doi: 10.1111/desc. 12288

Ronconi, L., Gori, S., Giora, E., Ruffino, M., Molteni, M., and Facoetti, A. (2013a). Deeper attentional masking by lateral objects in children with autism. Brain Cogn. 82, 213-218. doi: 10.1016/j.bandc.2013.04.006

Ronconi, L., Gori, S., Ruffino, M., Franceschini, S., Urbani, B., Molteni, M., et al. (2012). Decreased coherent motion discrimination in autism spectrum disorder: the role of attentional zoom-out deficit. PLOS ONE 7:e49019. doi: 10.1371/journal.pone.0049019

Ronconi, L., Gori, S., Ruffino, M., Molteni, M., and Facoetti, A. (2013b). Zoom-out attentional impairment in children with autism spectrum disorder. Cortex 49 , 1025-1033. doi: 10.1016/j.cortex.2012.03.005

Ropar, D., and Mitchell, P. (1999). Are individuals with autism and Asperger's syndrome susceptible to visual illusions? J. Child Psychol. Psychiatry 40, 1283-1293. doi: 10.1111/1469-7610.00544

Ropar, D., and Mitchell, P. (2001). Susceptibility to illusions and performance on visuospatial tasks in individuals with autism. J. Child Psychol. Psychiatry 42, 539-549. doi: 10.1111/1469-7610.00748

Rouse, H., Donnelly, N., Hadwin, J. A., and Brown, T. (2004). Do children with autism perceive second-order relational features? The case of the Thatcher illusion. J. Child Psychol. Psychiatry 45, 1246-1257. doi: 10.1111/j.14697610.2004.00317.x

Ruffino, M., Gori, S., Boccardi, D., Molteni, M., and Facoetti, A. (2014). Spatial and temporal attention are both sluggish in poor phonological decoders with developmental dyslexia. Front. Hum. Neurosci. 8:331. doi: 10.3389/fnhum.2014.00331

Ruffino, M., Trussardi, A. N., Gori, S., Finzi, A., Giovagnoli, S., Menghini, D., et al. (2010). Attentional engagement deficits in dyslexic children. Neuropsychologia 8, 3793-3801. doi: 10.1016/j.neuropsychologia.2010. 09.002

Ruzzoli, M., Gori, S., Pavan, A., Pirulli, C., Marzi, C. A., and Miniussi, C. (2011). The neural basis of the Enigma illusion: a transcranial magnetic stimulation study. Neuropsychologia 49, 3648-3655. doi: 10.1016/j.neuropsychologia.2011.09.020

Sacrey, L. A., Armstrong, V. L., Bryson, S. E., and Zwaigenbaum, L. (2014). Impairments to visual disengagement in autism spectrum disorder: a review of experimental studies from infancy to adulthood. Neurosci. Biobehav. Rev. 47, 559-577. doi: 10.1016/j.neubiorev.2014.10.011

Sarti, A., Malladi, R., and Sethian, J. A. (2000). Subjective surfaces: A method for completing missing boundaries. Proc. Natl. Acad. Sci. U.S.A. 97, 6258-6263. doi: $10.1073 /$ pnas. 110135797

Schiller, P. H., and Carvey, C. E. (2006). Demonstrations of spatiotemporal integration and what they tell us about the visual system. Perception 35, 1521-1555. doi: 10.1068/p5564

Schulte-Körne, G., and Bruder, J. (2010). Clinical neurophysiology of visual and auditory processing in dyslexia: a review. Clin. Neurophysiol. 121, 1794-1809. doi: 10.1016/j.clinph.2010.04.028
Shepard, R. N. (1981). "Psychological complementarity" in Perceptual Organization, eds M. Kubovy and J. R. Pomerantz (Hillsdale, NJ: Lawrence Erlbaum Associates), 279-342.

Shi, V., Cui, J., Troncoso, X. G., Macknik, S. L., and Martinez-Conde, S. (2013). Effect of stimulus width on simultaneous contrast. PeerJ 1:e146. doi: 10.7717/peerj.146

Simmons, D. R., Robertson, A. E., McKay, L. S., Toal, E., McAleer, P., and Pollick, F. E. (2009). Vision in autism spectrum disorders. Vis. Res. 49, 2705-2739. doi: 10.1016/j.visres.2009.08.005

Slaghuis, W. L., and Ryan, J. F. (1999). Spatio-temporal contrast sensitivity, coherent motion, and visible persistence in developmental dyslexia. Vis. Res. 39, 651-668. doi: 10.1016/S0042-6989(98)00151-5

Slaghuis, W. L., Twell, A. J., and Kingston, K. R. (1996). Visual and language processing disorders are concurrent in dyslexia and continue into adulthood. Cortex 32, 413-438. doi: 10.1016/S0010-9452(96)80002-5

Song, Y., Hakoda, Y., Sanefuji, W., and Cheng, C. (2015). Can they see it? The functional field of view is narrower in individuals with autism spectrum disorder. PLoS ONE 10:e0133237. doi: 10.1371/journal.pone.0133237

Soriano, M., Spillmann, L., and Bach, M. (1996). The abutting grating illusion. Vision Res. 36, 109-116. doi: 10.1016/0042-6989(95)00107-B

Sperandio, I., and Chouinard, P. A. (2015). The mechanisms of size constancy. Multisens Res. 28, 253-283. doi: 10.1163/22134808-00002483

Sperandio, I., Kaderali, S., Chouinard, P. A., Frey, J., and Goodale, M. A. (2013). Perceived size change induced by nonvisual signals in darkness: the relative contribution of vergence and proprioception. J. Neurosci. 33, 16915-16923. doi: 10.1523/JNEUROSCI.0977-13.2013

Sperandio, I., Lak, A., and Goodale, M. A. (2012). Afterimage size is modulated by size-contrast illusions. J. Vis. 12:18. doi: 10.1167/12.2.18

Sperandio, I., Savazzi, S., and Marzi, C. A. (2010). Is simple reaction time affected by visual illusions? Exp. Brain Res. 201, 345-350. doi: 10.1007/s00221-009-2023-y

Sperling, A. J., Lu, Z., Manis, F. R., and Seidenberg, M. S. (2005). Deficits in perceptual noise exclusion in developmental dyslexia. Nat. Neurosci. 8, 862-863. doi: $10.1038 / \mathrm{nn} 1474$

Sperling, A. J., Lu, Z. L., Manis, F. R., and Seidenberg, M. S. (2006). Motionperception deficits and reading impairment: it's the noise, not the motion. Psychol. Sci. 17, 1047-1053. doi: 10.1111/j.1467-9280.2006.01825.x

Spillmann, L. (2009). Phenomenology and neurophysiological correlations: two approaches to perception research. Vis. Res. 49, 1507-1521. doi: 10.1016/j.visres.2009.02.022

Spillmann, L., Hardy, J., Delahunt, P., Pinna, B., and Werner, J. S. (2010). Brightness enhancement seen through a tube. Perception 39, 1504-1513. doi: $10.1068 / \mathrm{p} 6765$

Stein, J. (2001). The magnocellular theory of developmental dyslexia. Dyslexia 7, 12-36. doi: 10.1002/dys.186

Stein, J. (2014). Dyslexia: the role of vision and visual attention. Curr. Dev. Disord. Rep. 1, 267-280. doi: 10.1007/s40474-014-0030-6

Stein, J., and Walsh, V. (1997). To see but not to read; the magnocellular theory of dyslexia. Trends Neurosci. 20, 147-152. doi: 10.1016/S0166-2236(96)01005-3

Steinman, S. B., Steinman, B. A., and Garzia, R. P. (1998). Vision and attention. II: Is visual attention a mechanism through which a deficient magnocellular pathway might cause reading disability? Optom. Vis. Sci. 75, 674-681. doi: 10.1097/00006324-199809000-00023

Sterzer, P., Haynes, J. D., and Rees, G. (2006). Primary visual cortex activation on the path of apparent motion is mediated by feedback from hMT+/V5. Neuroimage 32, 1308-1316. doi: 10.1016/j.neuroimage.2006.05.029

Stroganova, T. A., Orekhova, E. V., Prokofyev, A. O., Posikera, I. N., Morozov, A. A., Obukhov, Y. V., et al. (2007). Inverted event-related potentials response to illusory contour in boys with autism. Neuroreport 18, 931-935. doi: 10.1097/WNR.0b013e32811e151b

Tallal, P. (2004). Improving language and literacy is a matter of time. Nat. Rev. Neurosci. 5, 721-728. doi: 10.1038/nrn1499

Ternus, J. (1938). ““Experimentelle untersuchung uber phanomenale identitat” psychologische forschung 7 81: 135 [English translation as "the problem of phenomenal identity,"” in A Source Book of Gestalt Psychology, ed. W. D. Ellis (London: Routledge and Kegan Paul), 149-160.

Thompson, P. (1980). Margaret Thatcher: a new illusion. Perception 9, 483-484. doi: $10.1068 / \mathrm{p} 090483$ 
Titchener, E. B. (1901). Experimental Psychology: Quantitative Experiments. London: Macmillan.

Todorović, D. (2006). Lightness, illumination, and gradients. Spat. Vis. 19, 219-261. doi: $10.1163 / 156856806776923407$

Turatto, M., Benso, F., Facoetti, A., Galfano, G., Mascetti, G. G., and Umiltà, C. (2000). Automatic and voluntary focusing of attention. Percept. Psychophys. 62, 935-952. doi: 10.3758/BF03212079

Valdois, S., Gérard, C., Vanault, P., and Dugas, M. (1995). Peripheral developmental dyslexia: a visual attentional account? Cogn. Neuropsychol. 12, 31-67. doi: 10.1080/02643299508251991

Valentine, T., and Bruce, V. (1985). What's up? The margaret thatcher illusion revisited. Perception 14, 515-516. doi: 10.1068/p140515

Varin, D. (1971). Fenomeni di contrasto e diffusione cromatica nell'organizzazione spaziale del campo percettivo. Rivista Psicol. 65, 101-128.

Victor, J. D., Conte, M. M., Burton, L., and Nass, R. D. (1993). Visual evoked potentials in dyslexics and normals: failure to find a difference in transient or steady-state responses. Vis. Neurosci. 10, 939-946. doi: $10.1017 /$ S0952523800006155

Vidyasagar, T. R. (1999). A neuronal model of attentional spotlight: parietal guiding the temporal. Brain Res. Rev. 30, 66-76. doi: 10.1016/S0165-0173(99) 00005-3

Vidyasagar, T. R. (2013). Reading in to neuronal oscillations in the visual system: implications for developmental dyslexia. Front. Hum. Neurosci. 7:811. doi: 10.3389/fnhum.2013.00811

Vidyasagar, T. R., and Pammer, K. (1999). Impaired visual search in dyslexia relates to the role of the magnocellular pathway in attention. Neuroreport 10 , 1283-1287. doi: 10.1097/00001756-199904260-00024

Vidyasagar, T. R., and Pammer, K. (2010). Dyslexia: a deficit in visuo-spatial attention, not in phonological processing. Trends Cogn. Sci. 14, 57-63. doi: 10.1016/j.tics.2009.12.003

Vlamings, P. H., Jonkman, L. M., van Daalen, E., van der Gaag, R. J., and Kemner, C. (2010). Basic abnormalities in visual processing affect face processing at an early age in autism spectrum disorder. Biol. Psychiatry 68, 1107-1113. doi: 10.1016/j.biopsych.2010.06.024

Wallach, A. (1935). Über visuell wahrgenommene bewegungsrichtung. Psychol. Forsch. 20, 325-380. doi: 10.1007/BF02409790

Walter, E., Dassonville, P., and Bochsler, T. M. (2009). A specific autistic trait that modulates visuospatial illusion susceptibility. J. Autism Dev. Dis. 39, 339-349. doi: 10.1007/s10803-008-0630-2

Weintraub, D. J. (1979). Ebbinghaus illusion: context, contour, and age influence the judged size of a circle amidst circles. J. Exp. Psychol. 5:353.
Wickelgren, B. G. (1965). Brightness contrast and length perception in the Müller-Lyer illusion. Vision Res. 5, 141-150. doi: 10.1016/0042-6989(65) 90062-3

Williams, M., Brannan, J., and Lartigue, E. (1987). Visual search in good and poor readers. Clin. Vis. Sci. 1, 367-371.

Williams, M. J., Stuart, G. W., Castles, A., and McAnally, K. I. (2003). Contrast sensitivity in subgroups of developmental dyslexia. Vision Res. 43, 467-477. doi: 10.1016/S0042-6989(02)00573-4

Wright, B. A., Bowen, R. W., and Zecker, S. G. (2000). Nonlinguistic perceptual deficits associated with reading and language disorders. Curr. Opin. Neurobiol. 10, 482-486. doi: 10.1016/S0959-4388(00)00119-7

Yazdanbakhsh, A., and Gori, S. (2008). A new psychophysical estimation of the receptive field size. Neurosci. Lett. 438, 246-251. doi: 10.1016/j.neulet.2008.04.040

Yazdanbakhsh, A., and Gori, S. (2011). Mathematical analysis of the Accordion Grating illusion: a differential geometry approach to introduce the 3D aperture problem. Neural Netw. 24, 1093-1101. doi: 10.1016/j.neunet.2011.06.016

Zanuttini, L. (1996). Figural and semantic factors in change in the Ebbinghaus illusion across four age groups of children. Percept. Mot. Skills 82, 15-18. doi: 10.2466/pms.1996.82.1.15

Zhao, J., Qian, Y., Bi, H. Y., and Coltheart, M. (2014). The visual magnocellulardorsal dysfunction in Chinese children with developmental dyslexia impedes Chinese character recognition. Sci. Rep. 4:7068. doi: 10.1038/srep 07068

Zöllner, F. (1860). Ueber eine neue Art von Pseudoskopie und ihre Beziehungen zu den von Plateau und Oppel beschriebenen Bewegungsphänomenen. Ann. Physik. 186, 500-523. doi: 10.1002/andp.18601860712

Zorzi, M., Barbiero, C., Facoetti, A., Lonciari, I., Carrozzi, M., Montico, M., et al. (2012). Extra-large letter spacing improves reading in dyslexia. Proc. Natl. Acad. Sci. U.S.A. 109, 11455-11459. doi: 10.1073/pnas.1205566109

Conflict of Interest Statement: The authors declare that the research was conducted in the absence of any commercial or financial relationships that could be construed as a potential conflict of interest.

Copyright (C) 2016 Gori, Molteni and Facoetti. This is an open-access article distributed under the terms of the Creative Commons Attribution License (CC BY). The use, distribution or reproduction in other forums is permitted, provided the original author(s) or licensor are credited and that the original publication in this journal is cited, in accordance with accepted academic practice. No use, distribution or reproduction is permitted which does not comply with these terms. 